\title{
Influence of adhesive bond line thickness on joint strength
}

\author{
P. Davies ${ }^{a,}{ }^{*}$, L. Sohier ${ }^{b}$, J.-Y. Cognard ${ }^{c}$, A. Bourmaud ${ }^{d}$, D. Choqueuse ${ }^{a}$, E. Rinnert ${ }^{e}$ and R. \\ Créac'hcadec $^{\text {b, c }}$
}

\footnotetext{
${ }^{a}$ Materials and Structures group, IFREMER Brest Centre, 29280 Plouzané, France

${ }^{b}$ LBMS, Université de Bretagne Occidentale, 29285 Brest, France

c LBMS, ENSIETA, 29806 Brest, France

d L2PIC, Université de Bretagne Sud, 56321 Lorient, France

e Interfaces Group, IFREMER Brest Centre, 29280 Plouzané, France
}

*: Corresponding author: Davies P., Tel.: +33 29822 4777; fax: +33 29822 4535, email address : Peter.Davies@ifremer.fr

\begin{abstract}
:
While the geometry of aerospace assemblies is carefully controlled, for many industrial applications such as marine structures bond line thickness can vary significantly. In this study epoxy adhesive joints of different thicknesses between aluminium substrates have been characterized using physicochemical analyses (differential scanning calorimetry, DSC; dynamic mechanical analysis, DMA; spectroscopy), nano-indentation and mechanical testing. Thermal analyses indicated no influence of thickness on structure. Nano-indentation revealed no evidence of an interphase at the metal/epoxy interface, nor any change in modulus for different thicknesses, though Raman spectroscopy suggested there may be slight variations in composition close to the substrates. However, mechanical testing using the modified Arcan fixture indicated a significant drop in strength and failure strain under pure tension and a smaller reduction for tension/shear and pure shear loads as thickness increased. Examination of sections through joints did not indicate any physical reason for this, but numerical analysis of the stress state revealed larger stress concentration factors for tensile loading in thick joints, which may explain the thickness effect. It is recommended that joint thickness should be kept below $0.8 \mathrm{~mm}$ to avoid obtaining artificially low values with the Arcan test.
\end{abstract}

Keywords: Epoxy; Aluminium; Mechanical properties; Arcan 


\section{Introduction}

Adhesive bonding is now an established joining method which has been reviewed in detail recently [1]. It is a particularly attractive assembly technique for applications where weight gain is at a premium, and racing yachts are one such example. However, the large scale of structures such as boat hulls results in significant dimensional variations, so that it is not possible to achieve the thin bond lines and tight tolerances imposed in bonded aerospace structures. It is therefore essential to be able to characterize the influence of this parameter, and this was the aim of the present study. There have been several previous studies in this area using two approaches, based on either fracture mechanics or stress analysis. Kinloch [2] reviewed some early studies of both types. For lap shear specimens, the simple stress analyses for this geometry indicate a strong increase in failure stress with increasing joint thickness while measurements and finite element analysis indicate much lower sensitivity to this parameter [3]. In early studies on bond line thickness Bascom and colleagues [4] and then Kinloch \& Shaw [5] used linear elastic fracture mechanics tests to characterize the crack propagation resistance of joints up to $3 \mathrm{~mm}$ thick. They found an optimum joint thickness around $0.5 \mathrm{~mm}$, and postulated that there is competition between a constraint mechanism, due to the rigid substrates, at low thickness, resulting in high tensile stresses, and the amount of dissipation in the plastic zone which increases to a maximum then reduces at higher thickness. The following expression was proposed for the optimal joint thickness $h$, based on the fully developed plastic zone radius $\left(r_{p}\right)$, for plane stress and linear elastic fracture mechanics [5]:

$$
h=2 r_{p}=\frac{1}{\pi}\left(\frac{E G_{c}}{\sigma_{y}^{2}}\right)
$$

where $\mathrm{E}$ is the adhesive modulus, $\mathrm{G}_{\mathrm{c}}$ the critical strain energy release rate and $\sigma_{\mathrm{y}}$ the yield stress. A peak in toughness versus bond line thickness can be expected when $r_{p}$ equals the latter. These results were cited by Kinloch \& Moore [6], who presented further data which showed the same trend. More recently Kawashita et al. presented peel test data from aluminium joints with bond line thicknesses of $0.1,0.25$ and $0.4 \mathrm{~mm}$, below the optimal thickness, for two epoxy adhesives [7]. Measured toughness increased with thickness and a reasonable fit was obtained between test results and their LEFM model. Mall and Ramamurthy used double cantilever beam specimens to examine fracture and crack growth under cyclic loading in joints of different thicknesses [8]. DCB joints with different adhesive thickness showed similar thresholds at lower crack growth rates, whereas a thicker adhesive layer resulted in an improved resistance to the crack growth for high propagation rates. Gleich 
et al. also used a fracture mechanics approach, to show that the stress intensity factors, after an initial decrease in the low bondline thickness range, increased with increasing bondline thickness [9]. In another study, using the more traditional stress-based approach, Tomblin et al [10] presented results from thick adherend shear test (TAST) and thin adherend lap shear specimens with adhesive thicknesses in a wide range from 0.4 to $3 \mathrm{~mm}$. Their aim was to produce stress-strain data for design of secondary bonded assemblies in general aviation applications, for which joints may be thicker than the previously-standard $0.25 \mathrm{~mm}$ thickness. They noted a decrease in apparent shear strength with increasing joint thickness for the three adhesives tested on aluminium substrates with both tests. TAST specimens gave consistently higher values than thin adherend lap shear specimens at all bond line thicknesses, due to the development of peel stresses in the latter. Grant et al also presented results from tests on lap shear specimens which showed a linear drop in failure load as bond-line thickness was increased from 0.1 to $3 \mathrm{~mm}$, and they attributed this to an increase in bending stress for the thicker adhesives [11]. Taib et al recently showed results for L-section joints with adhesive thicknesses of $0.127,0.635$ and $2.54 \mathrm{~mm}$ [12]. Failure loads dropped from 8.27 to $3.9 \mathrm{kN}$ as joint thickness increased, and this was attributed to a change from plane stress to plane strain states. Finally, Jarry \& Shenoi examined 1, 5 and 10mm butt strap metallic assemblies bonded with a methacrylate adhesive and found similar strengths for 1 and $5 \mathrm{~mm}$ but significantly lower values for the thickest bond-line [13].

This summary of some of the previous work on bond line thickness, and the fact that many of the papers cited are very recent, underlines the importance of this subject. There is a tendency for measured failure stress to decrease with increasing bondline thickness, but interpreting variations in properties can be quite complex as various factors may intervene to modify the behaviour of joints as their thickness is increased:

First, the nature or dimensions of defects may vary with bond line thickness. Visual and microscopic examination can be used to check this effect.

Second, the adhesive structure may change as thickness increases. This may be caused by differences in cure conditions for example. Heterogeneous thermal behaviour, such as exotherm dissipation, will depend on the proximity of conductive substrates. Thermal analyses or local property measurements may enable such variations to be detected.

Thirdly, the adhesive/substrate interface properties may be modified as thickness increases. This may be due to internal stresses developing at this interface [14], to migration of species from the substrates into the adhesive 
(oxides) or to changes of stoichiometry within the adhesive near the substrate. Roche and colleagues have examined these phenomena in detail [15]. Many techniques have been used to detect interphases, based on changes in chemical state (by Infra-Red spectroscopy or micro-thermal analysis for example [16]) or mechanical properties (tensile, nano-indentation or even laser acoustic methods [17]).

Fourthly, the energy dissipating mechanisms (plasticity, damage development) may be modified by changing the distance between the substrates. Careful mechanical testing can be used to illustrate this.

- $\quad$ Finally, the change in specimen geometry with increasing bond line thickness may cause a change in the stress state within the joint so that tests on specimens with different thicknesses are not measuring the same properties. In order to examine this detailed stress analysis of the joint is required.

In the present paper these different factors will be examined using various techniques, in order to conclude on the influence of joint thickness on the mechanical behaviour of aluminium substrates bonded with a tough epoxy adhesive. Here we focus mainly on the non-linear behaviour of the adhesive rather than crack propagation.

\section{Materials}

The adhesive examined here is a two-part system. 100 parts by weight of a DGEBA (diglicidyl ether of bisphenol A) epoxy pre-polymer are mixed with 40 parts of TTD (trioxatridecane diamine) hardener, previously marketed as Redux 420, now Araldite 420 supplied by Huntsman. This adhesive has been widely-used for many years, in both the aerospace and marine industries. It contains some spherical fillers, estimated from burn-off to represent around $8 \%$ by weight. EDX (Energy Dispersive X-ray) analysis in the electron microscope indicated these to be solid glass spheres as will be described below. The choice of a commercial adhesive for this study, rather than a model epoxy, was made so that the results would be of direct interest for industrial assemblies. However, the complex formulation does make interpretation of results more complicated. The substrates are aluminium 2017 grade alloy.

\section{Specimen preparation}

Adhesive film samples, for DSC (Differential Scanning Calorimetry), DMA (Dynamic Mechanical Analysis), and tensile tests, were produced by mixing the adhesive and hardener 
and casting films of different thicknesses between two acetal blocks, with spacers to define joint thickness. Bonded aluminium assembly specimens for mechanical testing in the Arcan fixture were prepared in two special jigs, enabling twelve specimens to be bonded at a time, one of which is shown in Figure 1. Surface preparation of the substrates was abrasion with 120 grade abrasive paper, an acetone wipe to remove dust particles followed by careful drying. Substrate surface roughness Ra was measured to be between 1.7 and $2.2 \mu \mathrm{m}$.

Some specimens were tested in the Arcan test fixture, samples for DSC were then removed directly from fracture surfaces. Others were sectioned by a high pressure water jet into three parts, which created 6 surfaces for microscopic inspection and nano-indentation, Figure $1 \mathrm{~b}$. The cure cycle for all samples was 24 hours at $20^{\circ} \mathrm{C}$, followed by 4 hours at $50^{\circ} \mathrm{C}$. This was chosen as it is a commonly applied cycle in racing yacht construction. Higher cure temperatures are not easy to apply in boatyards where the structures to be assembled may be tens of metres long. This cure cycle has been shown in a previous study to result in a Tg value around $50^{\circ} \mathrm{C}[18]$.

\section{Experimental techniques}

In order to establish whether the polymer structure and its interface with the substrates were affected by changing the joint thickness various analyses were performed before the mechanical properties were measured. These included microscopic examination, thermal analysis, nano-indentation, and Raman spectroscopy. Then tensile tests on cast films and Arcan tests on bonded assemblies were performed.

\subsection{Microscopic examination}

Untested bonded aluminium test samples, of the geometry used to measure mechanical properties, were sectioned by water jet cutting (Figure 1b) and polished. These were then examined using both optical microscopy and an FEI Quinta 200 scanning electron microscope. For the latter a thin Au-Pd coating was applied to avoid charging. An energy dispersion spectrometry analyser (INCA from Oxford Instruments) was used to detect elements within the joint.

\subsection{Thermal analysis}

DSC analysis was performed on samples of around $10 \mathrm{mg}$ removed from cast films and Arcan fracture surfaces, in a scanning DSC (TAI 2920), at a heating rate of $3^{\circ} \mathrm{C} /$ minute. DMA (Dynamic Mechanical Analysis) was performed on cast adhesive samples using TAI 2980 
equipment in the tension mode at a frequency of $1 \mathrm{~Hz}$, on $10 \mathrm{~mm}$ wide, $35 \mathrm{~mm}$ long film samples clamped at both ends. These were also heated at $3^{\circ} \mathrm{C} /$ minute, from 20 to $120^{\circ} \mathrm{C}$.

\subsection{Nano-indentation}

Depth sensing indentation (DSI), often referred to as nanoindentation is a powerful technique enabling local variations in modulus to be measured [19]. Many authors have investigated interphase regions in various materials by using nanoindentation. For example, Zhu et al. [20] studied modulus and hardness of PVC/rubber blends using nanoindentation. They have shown an interface region characterized by an abrupt change in modulus and hardness. Bourmaud et al [21] investigated nanomechanical characteristics of recycled poly(carbonate)/crushed rubber blends by using nanoindentation. They revealed an interphase region between the matrix and the rubber particles. Lee et al [22] have used nanoindentation to evaluate interphase properties of a cellulose fiber-reinforced polypropylene composite; hardness and modulus in the transition region were used to charecterise its mechanical properties. Ureña et al. $[23,24]$ carried out nanoindentation in order to determine interfacial mechanical properties in carbon fiber/aluminium matrix composites; they showed the effect of various coatings on the aluminium matrix. Kim et al [25] investigated the interphase of silane treated glass fiber composites and showed different interphase thicknesses according to the silane agent applied. These different studies show that nanoindentation is a powerful tool to determine the mechanical properties of various interphases.

There have been few previous applications of this technique to adhesive joints, but Zheng \& Ashcroft have used micro-indentation to measure in-situ modulus and compare values to those for bulk adhesives [26]. In using the nanoindentation method, sample preparation is very important because accurate results are obtained only if the indentations are significantly deeper than the surface topography of the specimen. Meticulous preparation can significantly reduce the uncertainty in determining the surface property when performing nanoindentation experiments [27].

Nanoindentation tests involve the contact of an indenter on a material surface and its penetration to a specified load or depth. Load is measured as a function of penetration depth. Figure 2 shows a typical load-penetration curve (a) and an illustration of the unloading process showing parameters characterizing the contact geometry (b) [28]. In this case, penetration depth is the displacement into the sample starting from its surface. Calculation methods to determine modulus and hardness are based on the work of Oliver and Pharr [29]. 
From the load-penetration curve we can easily obtain the maximum displacement, $\mathrm{h}_{\max }$, the maximum load on the sample, $\mathrm{P}_{\max }$ and the contact stiffness, $\mathrm{S} . \mathrm{S}$ is the slope of the tangent line to the unloading curve at the maximum loading point. The contact depth, $\mathrm{h}_{\mathrm{c}}$ is related to the deformation behaviour of the material and the shape of the indenter. In fact $h_{c}=h_{\max }-h_{s}$ as shown on Figure 2:

$$
h_{c}=h_{\max }-\varepsilon \frac{P_{\max }}{S}
$$

where $\varepsilon$ is a constant that depends on the geometry of the indenter $(0.72$ for a Berkovich indenter). For a perfectly sharp Berkovitch indenter, projected area A can be calculated by Eq. (3) as follows:

$$
A=24.56 h_{c}^{2}
$$

The hardness is defined as the indentation load divided by the projected contact area, Eq. (4).

$$
H=\frac{P \max }{A}
$$

The effective elastic modulus $E_{r}$ can be calculated with the relationship in Eq. (5):

$$
S=2 a E_{r}=\frac{2 \beta}{\sqrt{\pi}} E_{r} \sqrt{A}
$$

where $\mathrm{a}$ is the contact radius and $\beta$ is a constant depending on the geometry of the indenter (1.034 for a Berkovitch tip). The reduced modulus, $\mathrm{E}_{\mathrm{r}}$, accounting for deformation of both the indenter and the sample, is given by:

$$
\frac{1}{E_{r}}=\frac{\left(1-v^{2}\right)}{E}+\frac{\left(1-v_{i}^{2}\right)}{E_{i}}
$$

In the equation above, $\mathrm{E}_{\mathrm{i}}(1140 \mathrm{GPa})$ and $v_{\mathrm{i}}(0.07)$ are the elastic properties of the diamond indenter. E and $v$ are the elastic modulus and Poisson's ratio of the sample.

Indentation tests were performed with a commercial nanoindentation system (Nanoindenter $\mathrm{XP}$, MTS Nano Instruments) at room temperature $(23 \pm 1)^{\circ} \mathrm{C}$ with a continuous stiffness measurement (CSM) technique. In this technique, an oscillating force at controlled frequency and amplitude is superimposed onto a nominal applied force. The material, which is in contact with the oscillating force, responds with a displacement amplitude and phase angle.

A three-sided pyramid (Berkovitch) diamond indenter was employed for the indentation tests. The area function, which is used to calculate contact area Ac from contact depth $h_{c}$, was carefully calibrated by using a standard sample, prior to the experiments. 
The nanoindentation system is coupled with an optical microscope in order to control the surface of the sample in situ. The precise coordinates of the position of the indent are determined simultaneously to the observation of the surface.

Strain rate during loading was maintained at $0.05 \mathrm{~s}^{-1}$ for all the samples. We operated with a 3 $\mathrm{nm}$ amplitude, $70 \mathrm{~Hz}$ oscillation using identical load rate conditions. The nanoindenter tests were carried out in the following sequence: first, after the indenter made contact with the surface, it was driven into the material at a constant strain rate, $0.05 \mathrm{~s}^{-1}$ to a depth of $100 \mathrm{~nm}$; secondly, the load was held at maximum value for $60 \mathrm{~s}$; and finally, the indenter was withdrawn from the surface with the same rate as during loading until $10 \%$ of the maximum load was reached.

Figure $3 \mathrm{a}$ shows an example of two lines of 40 indents at the metal/epoxy interface. The distance between two indents is 2 microns. It is easy to see the two lines of indents in the aluminium, the lines continue into the epoxy above. Figure $3 \mathrm{~b}$ shows an example of a single indent in the aluminium, Figure $3 \mathrm{c}$ shows an indent in the epoxy. The surfaces were polished using progressively finer paper then down to 0.5 microns diamond paste.

\subsection{Spectroscopic analysis}

There are various spectroscopic techniques which allow local measurements of molecular structure to be made on polymers [30]. A Thermo Nicolet Infrared microscope was used first, to try to obtain local spectra in reflection, but the reflected signal was too weak to allow reliable analysis due to the high infrared absorption coefficients of epoxy samples. Measurements might be possible in transmission but this would require very careful preparation of thin sections. However, this equipment can only make measurements with a spot greater than $100 \mu \mathrm{m}^{2}$, due to unfavourable spatial resolution of the microscope in the infrared spectral domain. A solution is to carry out vibrational spectroscopy on epoxy samples using Raman scattering spectroscopy; this provides similar information on sample features but it allows measurements even if substrates strongly absorb infrared radiation. Using a visible laser, high spatial resolution can be obtained. Raman scattering spectra were collected on a Jobin-Yvon LabRam HR800 spectrometer equipped with an Olympus BX41 optical microscope, an adjustable angle notch filter and an air cooled Andor iDus CCD camera. The excitation was induced by a laser beam of a Sacher Lion Diode at a wavelength of $784.4 \mathrm{~nm}$. This equipment is in a controlled environment laboratory at $20^{\circ} \mathrm{C} \pm 1^{\circ} \mathrm{C}$. The beam was focused using a $100 \mathrm{x}$ objective lens (numerical aperture $=0.90$ ) on an area of about $3 \mu \mathrm{m}^{2}$. The laser power on the sample was approximately $20 \mathrm{~mW}$. The back-scattered Raman spectra 
were collected in a confocal mode to avoid optical artefacts. With a $6001 / \mathrm{mm}$ grating, the spectral resolution at $838 \mathrm{~nm}$ was $2.5 \mathrm{~cm}^{-1}$, with a wavenumber precision better than $1 \mathrm{~cm}^{-1}$. The wave-number calibration is obtained by recording the band for silicon, located at 521 $\mathrm{cm}^{-1}$. The microscope is equipped with a $\mathrm{x}, \mathrm{y}, \mathrm{z}$ motorized stage which allows mapping acquisition in autofocus mode. 21 spectra were recorded each $2.5 \mu \mathrm{m}$ along a cross section of $50 \mu \mathrm{m}$ on a thin $(0.1 \mathrm{~mm}$ thickness $)$ assembly sample. In this paper results from only 13 spectra are presented for clarity (see below).

\subsection{Mechanical tests}

The adhesive alone, in the form of parallel and dog-bone specimens cut from cast films of different thicknesses, was first tested in tension on an Instron 4302 test frame with a $500 \mathrm{~N}$ load cell. Loading rate was $2 \mathrm{~mm} /$ minute. Extension was measured on some parallel sided $10 \mathrm{~mm}$ wide specimens using a clip-on Instron 2620-602 extensometer with 25mm gauge length, but for the thinnest films $(<0.5 \mathrm{~mm})$ the weight of the extensometer tended to deform the specimen, so results were not reliable and are not presented. Tensile strength was measured on dog-bone samples, with a central width of $10 \mathrm{~mm}$ and polished edges. Then bonded aluminium joints were tested, in a modified Arcan fixture. This has been described in detail previously [18,31]. Figure 4 shows the fixture. By changing the angle of the fixture with respect to the machine loading axis loads from pure shear to pure tension can be applied. Three types of loading were applied here, tension (loading with the fixture at $0^{\circ}$ to the machine axis), shear (loading with the fixture at $90^{\circ}$ as shown in Figure 4) and a balanced combination of tension and shear, by orienting the specimen at $45^{\circ}$ to the loading axis. Loading rate was $0.5 \mathrm{~mm} /$ minute for all samples. This will result in a slightly lower strain rate for thicker bondline thicknesses, but results from previous studies suggest that this difference will not change the response significantly [32].

The beaks, Figure 4c, enable a more uniform stress state to be achieved, but a correction is applied to account for the small stress concentrations revealed by numerical analysis [18]. From the measured load and analysis of images of the displacements of the substrates during the tests the mean stress can be plotted versus displacement (tangential DT or normal DN) divided by joint thickness $h$. The direct study of displacements and strains within the bonded joint is difficult due to the presence of the beaks and because the surface is not perfectly flat at the edges of the specimen. As the adhesive thickness is small the displacements of the substrates are used to determine strain in the joint. However, this measurement requires validation if homogeneous strain through the joint thickness is to be assumed. In order to 
check this by analysing the displacements through the thickness of the bonded joint a special specimen was prepared, with a $1.1 \mathrm{~mm}$ thick adhesive bond-line and with the beak removed in one zone studied with the camera; thus, by analysing a small zone it is possible to determine the kinematics of the bonded joint deformation. The digital camera system employed has been described previously [31]. For this test the sample was tested in pure shear, the crosshead displacement rate of the tensile testing machine was $0.5 \mathrm{~mm} / \mathrm{min}$ and an image was recorded every second. On the images the thickness of the bonded joint $(1.1 \mathrm{~mm})$ is represented with nearly 550 pixels. The zone studied is a rectangle of 600 pixels x 230 pixels, which allows the analysis of the displacement of $400 \times 100$ points in the adhesive. Figure 5 presents the geometry of the zone studied, and a representation of the measured displacement field in the adhesive joint at time $\mathrm{t}=60 \mathrm{~s}$. The displacement field appears to have a linear evolution with respect to the $\mathrm{x}$-axis (horizontal axis); at this time the relative displacement of the two ends of the adhesive joint is DT $=0.042 \mathrm{~mm}$ (during loading, displacements of both substrates are observed). Then, after obtaining the displacement fields in the zones studied by image correlation at each time, an optimisation technique is used to obtain a representation of the displacement field of the adhesive. The vertical component of the displacement field in the adhesive $\left(\mathrm{V}_{\mathrm{Ri}}\right)$ is required at a given time, at each point $\mathrm{M}_{\mathrm{i}}\left(\mathrm{X}_{\mathrm{i}}, \mathrm{Y}_{\mathrm{i}}\right)$, in the following form:

$$
\mathrm{V}_{\mathrm{Ri}}=\mathrm{a}+\mathrm{b} \mathrm{X}_{\mathrm{i}}
$$

where $\mathrm{a}$ and $\mathrm{b}$ are constants. The two unknowns $\{\mathrm{a}, \mathrm{b}\}$ are obtained by the minimization of the difference between the modelled values of displacement and the values measured for the points $\mathrm{M}_{\mathrm{i}}$ : $\left(\mathrm{U}_{\mathrm{Mi}}, \mathrm{V}_{\mathrm{Mi}}\right) ; \mathrm{U}_{\mathrm{Mi}}$ and $\mathrm{V}_{\mathrm{Mi}}$ are the horizontal and vertical components of the displacement. Here only the vertical component of the displacement is used in order to analyse the adhesive deformation, the horizontal component of the displacement is much smaller than the vertical one. The values of measured displacements are known for $\mathrm{N}$ pixels of the zone of study. By solving the following problem:

$$
\text { Minimization of } \Sigma_{(\mathrm{i}=1, \mathrm{~N})}\left\{\left(\mathrm{V}_{\mathrm{Ri}}-\mathrm{V}_{\mathrm{Mi}}\right)^{2}\right\}
$$

the unknowns are the solutions of a linear problem with two equations for each time:

$$
\left[\begin{array}{cc}
\mathrm{N} & \Sigma\left(\mathrm{X}_{\mathrm{i}}\right) \\
\Sigma\left(\mathrm{X}_{\mathrm{i}}\right) & \Sigma\left(\mathrm{X}_{\mathrm{i}}\right)^{2}
\end{array}\right]\left[\begin{array}{l}
\mathrm{a} \\
\mathrm{b}
\end{array}\right]=\left[\begin{array}{c}
\Sigma\left(\mathrm{V}_{\mathrm{i}}\right) \\
\Sigma\left(\mathrm{X}_{\mathrm{i}} \mathrm{V}_{\mathrm{i}}\right)
\end{array}\right]
$$

In fact, for each image we obtain a representation of the displacement in the thickness of the adhesive. In order to evaluate this representation the following error indicator is defined:

$$
\zeta=\frac{1}{\mathrm{~N}}\left\{\Sigma_{(\mathrm{i}=1, \mathrm{~N})}\left\{\left(\mathrm{a}+\mathrm{b} \mathrm{X}_{\mathrm{i}}-\mathrm{V}_{\mathrm{Mi}}\right)^{2}\right\}\right\}^{0.5}
$$


$\zeta$ represents the average distance between the modelled values of displacement and those measured.

As the texture of the adhesive changes during loading and as the displacements are quite large, the image analysis is performed in several steps, in order to obtain better results; thus to take into account the complete displacement history, an upper bound of the error indicator $(\eta)$ is proposed. Figure 6-a shows the time evolution of the error indicators; the values are in $\mathrm{mm}$ and have to be compared to the relative displacement of the two ends of the adhesive joint, DT, at each time (figure 6-b). The minimal value of detectable displacement by image correlation using multi-scale resolution techniques is less than 0.05 pixel, for images coded in 8 bits. Therefore, for the scale factor used, which corresponds to nearly 500 pixels per mm, the order of magnitude of minimal measurable displacement is lower than $1 \times 10^{-4} \mathrm{~mm}$. The previous analysis is therefore quite accurate and errors are very small (Figure 5).

Figure 7 summarizes the results from this study; for different points on the loading curve it shows the deformation across the adhesive joint and a linear regression representation of the displacements in the thickness of the joint (thick white line). The assumption of homogeneous deformation in the adhesive appears justified in the case of shear loading. The behaviour of the adhesive close to the interface adhesive-substrate seems to be similar to that in the centre of the joint, but a precise analysis of this zone is quite difficult as the surface of the substrate is not perfectly flat. In order to establish the reproducibility of the method shear tests were then performed on four nominally identical specimens prepared at the same time under identical conditions. Figure 8 shows the results, and it is apparent that the response is quite reproducible.

\section{Results and discussion}

\subsection{Microscopic examination}

Figure 9 shows SEM photos of sections through joints of two thicknesses. While some small defects are visible there is not a significant difference in terms of size or number of defects between the two sections, and no significant difference was noted in other sections examined. The spherical inclusions noted above are clearly visible. EDX analysis was performed, the points across the joint in Figure 9a show the positions of one line of measurements. These indicated no significant change in composition, but EDX sensitivity to 
the light elements $\mathrm{C}, \mathrm{O}$ and $\mathrm{N}$ is limited. Analysis of the spheres clearly identified these to be mainly silicon.

\subsection{Thermal analysis}

Figure 10a shows examples of the reversible part of DSC recordings for two samples of different thickness. The values of glass transition temperature, $\mathrm{Tg}$, defined as the point of inflexion on the reversible enthalpy versus temperature plot, are shown in Figure 10b for samples taken from joint fracture surfaces and from cast film samples. There is little significant variation, all values are in the range 47 to $54^{\circ} \mathrm{C}$, even though slightly higher values are noted for the thinnest bond lines. If the substrate has modified the adhesive stoichiometry over a significant difference (tens of microns) as was shown in previous studies by Roche [15] when a higher hardener concentration was detected close to the substrate, one would expect this to be revealed as a higher value of $\mathrm{Tg}$ for the thinnest joint. This is not the case here. The values for the adhesive joints appear very similar to those obtained on thin and thick bulk film specimens. When the temperature exceeds the Tg a small irreversible exothermic peak was noted on the DSC plot. This indicates that cross-linking is not complete, and a higher temperature cure would allow a higher $\mathrm{Tg}$ to be obtained, as has been discussed elsewhere $[18,33]$. DMA also allowed $\mathrm{Tg}$ values to be obtained. According to the definition used (change in slope of E', peak tangent $\delta$ ) these differ slightly from DSC values, but DMA studies again indicated no difference in the small strain visco-elastic behaviour at different thicknesses. Overall these thermal analysis results do not indicate any change in global properties for different thicknesses of film or bond-line.

\subsection{Nano-indentation}

Nano-indentation was used to examine two aspects of the joints; first, to check the modulus of joints in-situ, by indenting at mid-thickness, and second to examine the substrate/adhesive interface region in order to determine whether an interphase was present. The results from the check on modulus are presented in Table 1 . These show very similar modulus values at the centre of each joint, with a slight tendency towards higher values as thickness increases.

\begin{tabular}{|c|c|}
\hline Joint thickness, mm & Modulus, GPa \\
\hline 0.33 & $2.45(0.11)$ \\
0.65 & $2.63(0.19)$ \\
1.23 & $2.71(0.15)$ \\
\hline
\end{tabular}

Table 1. Measured modulus values, mean ( standard deviation) 
of 10 values for each sample, measured at mid-thickness by nano-indentation.

Figure 11 shows examples of results from nano-indentation tests on thin and thick samples. Results from 120 and 80 indents are shown for the thin and thick joints respectively. The results are shown with modulus plotted on a log scale to make it easier to see the adhesive values. There is a very sharp drop in modulus from the $70 \mathrm{GPa}$ values corresponding to the aluminium down to adhesive values of $2 \mathrm{GPa}$, in a region less than 5 microns wide. It is not possible to conclude on the existence of an interphase over such a small distance, as in this area indentations may be affected by interactions between the indenter and the metal surface roughness. One can certainly conclude however that there is no evidence of the presence of an interphase on the scale described by Roche and colleagues, which extended over tens of microns from the surface [15].

\subsection{Raman spectroscopy}

Even if an interphase with different modulus from the bulk adhesive is not detected by nanoindentation there may be a region whose composition is modified by the proximity of the substrate. The DSC results did not detect such a region, but those are global measurements. Raman spectroscopy measurements were made as shown in Figure 12a. Figure 12b shows examples of the spectra recorded. These spectra allow local variations in molecular species to be detected. Analysis of these results in terms of molecular groups is complicated, as this is a formulated commercial adhesive, however an assignment of infrared bands for the same adhesive is available from a previous study [34]. The Raman scattering results obtained here are in good agreement with that work. $\mathrm{C}=\mathrm{C}$ stretching bands of aromatic cycles occur at 1450 , 1514 and $1608 \mathrm{~cm}^{-1}$. C-O stretching modes are located at $1297 \mathrm{~cm}^{-1}$ for $\mathrm{CH}-\mathrm{OH}$ groups and are located at 1248 and $1231 \mathrm{~cm}^{-1}$ for $\varphi-\mathrm{O}$ bonds $\left(\varphi\right.$ being the aromatic $\mathrm{C}_{6} \mathrm{H}_{6}$ ). For aliphatic ether, bands are located at 1105 and $1112 \mathrm{~cm}^{-1}$. The ring deformation mode is located at 670

$\mathrm{cm}^{-1}$. Bending modes of $\varphi-\mathrm{H}$ appear not only at $1180 \mathrm{~cm}^{-1}$ but also at 630-638 and 809-822 $\mathrm{cm}^{-1}$. The broad and strong band which contains at least two components at 809 and $822 \mathrm{~cm}^{-1}$ is assigned typically to para-di-substituted benzenes out-of-plane $\mathrm{C}-\mathrm{H}$ bending. With a weaker intensity, para-di-substituted benzenes in-plane $\mathrm{C}-\mathrm{H}$ bending band are located at 630 and 639 $\mathrm{cm}^{-1}$.

Despite the intrinsic differences between infrared and Raman vibrational spectroscopy, the majority of the bands are observed in both IR and Raman spectra; the principal differences occur in terms of intensities. Generally, vibrational modes which are very active (strong 
bands) in infrared are inactive (weak bands) in Raman scattering and conversely. Thus, one of the advantages of Raman scattering spectroscopy is that the $\mathrm{C}=\mathrm{C}$ group has a strong stretching vibration band which is generally weak or inactive in infrared. This band can often be used to determine polymer conformations and to determine the extent of cross-linking [35]. As a consequence, $\varphi-H$ bending modes could be useful to observe the chemical vicinity of aromatic cycles so the $\mathrm{C}-\mathrm{H}$ bending bands and $\mathrm{C}=\mathrm{C}$ stretching bands behaviour has been examined along the joint cross section. These bands are plotted in figure 13 in two spectral regions from 610 to $670 \mathrm{~cm}^{-1}$ for $\mathrm{C}-\mathrm{H}$ bending and from 1580 to $1630 \mathrm{~cm}^{-1}$ for $\mathrm{C}=\mathrm{C}$ stretching.

The first spectral region exhibits a decrease of the $639 \mathrm{~cm}^{-1}$ bands to the benefit of the 630 one. As for the second spectral region, the $\mathrm{C}=\mathrm{C}$ stretching band located at $1604 \mathrm{~cm}^{-1}$ at the $\mathrm{y}=2.6 \mu \mathrm{m}$ position shifts to higher values around $1609 \mathrm{~cm}^{-1}$ and there are changes in width and shape. In order to study these variations through the cross section, figure 14 is obtained by plotting intensity ratio (left axis) and Raman shift (right axis) for each analysed point of the cross section.

The ratio is obtained by dividing the intensity of the band located at $630 \mathrm{~cm}^{-1}$ by the addition of the intensities of the bands located at 630 and $639 \mathrm{~cm}^{-1}$. The results are presented as a percentage. Variations are clearly present for both parameters ; the last $10 \mu \mathrm{m}$ before reaching the substrate show the largest variations. These results suggest that in the adhesive close to the interface the chemical behaviour of the aromatic cycle in the resin changes. Two hypotheses could be proposed: either the observed variations are due to stoichiometric ratio variation of hardener and polymer and/or they are due to different resin conformations between bulk and interface adhesive.

The results shown here are from a preliminary study to determine whether Raman spectroscopy can be useful in analysing adhesive joints. To interpret the results in more detail is beyond the scope of the present work, but it is clear that Raman spectroscopy provides a very sensitive tool to examine local variations in composition, and that for the joint studied here chemical changes appear to be localized to a very small region near the substrate, within $10 \mu \mathrm{m}$.

\subsection{Mechanical tests}

Mechanical tests were then performed, first on films then on bonded joints. Figure 15 shows examples of the first part of tensile stress-strain curves measured on parallel sided samples to determine modulus values for thin (mean $0.64 \mathrm{~mm}$ ) and thick (mean $1.25 \mathrm{~mm}$ ) specimens. 
Failures often occurred prematurely at the extensometer knife edges but tensile modulus values could be determined from initial slopes. These are very similar for both thickness ranges. The values are lower than those obtained by nanoindentation (Table 1), as is usually observed due to various factors including the higher loading rate for the latter, the stress state beneath the indenter and surface effects. Figure 16 shows tensile strengths from tests on dogbone specimens without the extensometer.

Results from these tests do not indicate an influence of thickness on tensile properties of cast films, suggesting that there is no intrinsic reason to expect an influence of thickness on adhesive joint behaviour. Jeandrau has shown that a reasonable estimation of joint properties may be obtained from bulk adhesive behaviour in some cases [36]. These tests also allowed values of $\mathrm{E}$ and $\sigma_{\mathrm{y}}$ to be determined, which can be introduced in the equation proposed by Kinloch \& Shaw (equation 1). A value of $G_{c}$ is also needed if $r_{p}$ is to be calculated, and this was measured during a previous study using tapered double cantilever beam (TDCB) specimens [37] to be around $1400 \mathrm{~J} / \mathrm{m}^{2}$. The calculated plastic zone size $r_{p}$ is then around $0.3 \mathrm{~mm}$, so the optimal joint thickness with respect to fracture energy is around $0.6 \mathrm{~mm}$.

Adhesively bonded joints were then tested in the modified Arcan fixture. Figure 17 shows examples of results from 12 specimens, indicating how bond line thickness affects the stress-strain response under tension, tension/shear and shear loading using the Arcan fixture. Mean stress is plotted versus displacement/thickness, as in order to determine the material behaviour law an inverse identification procedure is required [32].

There is an influence of bond-line thickness under shear and tension/shear loads on the plateau values, with a much larger influence for tensile loading. In all the cases examined here lower plateau values were obtained for thicker joints. The failure mode was cohesive for tensile loading but adhesive for shear and tension/shear loads. Failure stresses are higher in tension than in shear, but failure strains are much larger in shear. Figure 18 shows the deformation of a joint during pure shear loading before failure, the shear bands are clearly visible. It is interesting to note that the tensile strengths obtained on film samples are similar to the mean tensile stress at failure of the thickest joints, whereas considerably higher strengths were obtained on adhesive samples with thin bond-lines. The constraint on lateral movement imposed by the substrates has a strong effect on thin film behaviour, the Poisson effect in thicker films is more similar to that of bulk tensile specimens. Modulus values from bulk film tests are not compared with Arcan tensile results due to uncertainty in the very small strains measured in the latter. 


\subsection{Numerical analysis of the influence of joint thickness}

In order to understand the influence of bond line thickness noted in the previous section numerical modelling of the test geometry was performed, using CAST3M finite element software [38]. Figure 19a shows an SEM image of a polished section in the beak region and Figures $19 \mathrm{~b}$ and $\mathrm{c}$ show the model geometry.

A study of the stress distribution through the thickness of the adhesive joint, even assuming linear elastic behaviour of the components, requires refined meshes [39]. Various simulations have shown that good numerical results are obtained using meshes with at least 20 linear rectangular elements for a $0.1 \mathrm{~mm}$ thickness of adhesive [40]. The geometry of the specimens designed for the modified Arcan fixture is presented in Figure $18 \mathrm{~b}(B D=33 \mathrm{~mm}$, $O B=15 \mathrm{~mm}$ ). The model boundary conditions are anti-symmetric on the segment $O A$, in order to model only half of the structure and displacements are applied to the upper bound of the substrate $B D$ (in the y-direction for tensile loading and in the $\mathrm{x}$-direction for shear loading). Results are presented for aluminium substrates (Young's modulus: $E_{a}=80 \mathrm{GPa}$, Poisson's ratio: $v_{a}=0.3$ ); the material parameters for the adhesive joint are $E_{j}=2 \mathrm{GPa}, v_{j}=0.3$. Calculations were made in 2D (plane stress) for different thicknesses of the adhesive joint (h) under tensile loading $\left(0^{\circ}\right)$, tensile-shear loading $\left(45^{\circ}\right)$ and shear loading $\left(90^{\circ}\right)$ using the following parameters: $h=0.1 \mathrm{~mm}, d=0.5 \mathrm{~mm}, r_{0}=0.8 \mathrm{~mm}$ and $\alpha=45^{\circ}$ (see Figure 19c).

The equivalent von Mises stress is used to compare stress states and results are normalised to make analysis of the stress distributions easier; the von Mises equivalent stress is normalized to unity at the middle of the joint (point $O$, Figure 19b).

Figure 20 presents the value of the von Mises equivalent stress near the free edge of the joint (stress factor), normalized with respect to the value at the centre of the joint. An increase in the thickness of the adhesive joint increases the edge effects. It is important to note that the loading conditions have an influence on the edge effects, and these are larger for tensile loading than for shear. The influence of other parameters can be found in [41], for instance edge effects are larger for steel substrates than for aluminium ones with this experimental fixture. Figure 21 presents the maximum and minimum values of the von Mises equivalent stress in the thickness of the adhesive joint along the bond line (direction $x$ in Figure 19b). Two extreme cases are considered, joint thicknesses (h) of 0.1 and $1.6 \mathrm{~mm}$. These results show that not only the maximum stress (stress factor presented above, Figure 20) but also the stress distributions in the adhesive joint depend on the thickness of the adhesive joint. Moreover it is 
important to note that the stress gradients close to the free edges of the adhesive increase significantly with the joint thickness.

The results in Figures 20 and 21 clearly show that in order to obtain a valid characterization of adhesive joint behaviour using this test fixture it is necessary to limit the bond-line thickness. While it is hazardous to use numerical results to make quantitative statements the trends from tests and analyses suggest that for shear loading with this test fixture joints up to $0.8 \mathrm{~mm}$ may be used, while in tension it is preferable to keep the bond line thickness below $0.6 \mathrm{~mm}$.

\section{Conclusions}

This study has examined the physico-chemical and mechanical behaviour of aluminium substrates bonded with epoxy adhesive joints of different thicknesses. There is no evidence that changing the joint thickness results in significant modifications to the polymer structure, the interface region nor the presence of defects for this assembly, over the range from 0.2 to $1.3 \mathrm{~mm}$. More sophisticated analyses would be needed to reveal local changes in chemistry but variations detected by Raman spectroscopy and nano-indentation were confined to a very thin layer near the substrate, whose extent is similar to the substrate surface roughness. The tensile stiffness and strength of cast adhesive films showed no variation over the same range of thickness. For adhesively bonded aluminium assemblies tested using the modified Arcan fixture a small influence of bond line thickness was noted under shear and tension/shear loads; a small reduction in mechanical properties was noted as bond line thickness was increased. Under tensile loading a more pronounced effect was measured, with significantly lower yield stress and failure strain for thicker joints. Numerical analysis indicates that this is caused by a change in the stress state as thicker joints are tested. The stress concentrations are higher for tension loading than tension/shear and lowest in shear, and all increase with thickness. It is recommended that for this modified Arcan test bond line thickness be limited to $0.6 \mathrm{~mm}$ to characterize these joints in tension with this fixture, and to below $0.8 \mathrm{~mm}$ for tension/shear and pure shear. The thinner the joint the lower the edge effects and the lower the influence of test imperfections such as misalignment. Further work is focussing on the characterization of the effects of marine aging on the performance of these joints. 


\section{Acknowledgements}

The authors are grateful to Philippe Crassous (IFREMER), for help with the SEM observations.

\section{References}

[1] Adams RD (editor), Adhesive Bonding, Science, Technology and Applications, Woodhead Publishing, 2005.

[2] Kinloch AJ, Adhesion and Adhesives, Science and Technology, Chapman and Hall, 1987.

[3] Adams RD, Peppiatt NA, Stress Analysis of Adhesive-Bonded Lap Joints J. Strain Analysis, 1974, 9, 185-196.

[4] Bascom WD, Cottington RL, Timmons CO, Fracture reliability of structural adhesives, J. Appl Polymer Sci., Applied Polymer Symp., 32, 1977, 165-188.

[5] Kinloch AJ, Shaw SJ, The fracture resistance of a toughened epoxy adhesive, J. Adhesion, 1981, $12,59-77$.

[6] Kinloch AJ, Moore DR, The influence of adhesive bond line thickness on the toughness of adhesive joints, in The application of fracture mechanics to polymers, adhesives and composites, ed Moore DR, Elsevier 2004, 149-155.

[7] Kawashita LF, Kinloch AJ, Moore DR, Williams JG, The influence of bond line thickness and peel arm thickness on adhesive fracture toughness of rubber toughened epoxy-aluminium alloy laminates, Int Jadhesion \& Adhesives, 28, 2008, 199-210.

[8 ] Mall S, Ramamurthy G, Effect of bond thickness on fracture and fatigue strength of adhesively bonded composite joints, Int J. Adhesion \& Adhesives, 9, 1, 1989, 33-37.

[9] Gleich DM; Van Tooren MJL; Beukers A, A stress singularity approach to failure initiation in a bonded joint with varying bondline thickness, J. Adhes. Sci \& Tech., 15, 10, 2001, 1247-1259. [9] [10] Tamblin JS, Yang C, Harter P, Investigation of thick bond line adhesive joints, DOT/FAA/AR01/33, June 2001.

[11] Grant LDR, Adams RD, DaSilva LFM, Experimental and numerical analysis of single lap joints for the automotive industry, Int J. Adhesion \& Adhesives, 29, 2009, 405-413.

[12] Taib AA, Boukhili R, Achiou S, Gordon S, Boukehili H, Bonded joints with composite adherends. Part 1. Effect of specimen configuration, adhesive thickness, spew fillet and adherend stiffness on fracture, Int J. Adhesion \& Adhesives, 26, 2006, 226-236.

[13] Jarry E, Shenoi RA, Performance of butt strap joints for marine applications, Int J Adhesion and Adhesives 26, 2006, 162-176.

[14] Nairn JA, Energy release rate analysis for adhesive and laminate double cantilever beam specimens emphasizing the effect of residual stresses, Int. J Adhesion \& Adhesives, 20, (2000), 59-70. 
[15] Roche AA, Bouchet J, Bentadjine S, Formation of epoxy-diamine interphases, Int J Adhesion and Adhesives, 22, 2002, 431-441.

[16] Jansen I, Schneider D, Hassler R, Laser-acoustic, thermal and mechanical methods for investigations of bond lines, Int J. Adhesion \& Adhesives, 29, 2009, 210-216.

[17] Possart G, Presser M, Passlack S, Geiss PL, Kopnarski M, Brodyanski A, Steinmann P, Micromacro characterisation of DGEBA-based epoxies as a preliminary to polymer interphase modelling, Int J. Adhesion \& Adhesives (2008), doi:10.1016/j.ijadhadh.2008.10.001

[18] Cognard J.Y., Davies P., Sohier L., Créac'hcadec R., A study of the non-linear behaviour of adhesively-bonded composite assemblies, Composite Structures, Vol. 76, 2006, 34-46.

[19] Fischer-Cripps C., Nanoindentation, Springer 2002.

[20] Shui-Han Zhu, C.-M.C., Yiu-Wing Mai,, Micromechanical properties on the surface of PVC/SBR blends spatially resolved by a nanoindentation technique. Polymer Engineering and Science, 2004. 44(3): p. 609-614.

[21] Bourmaud, A., et al., Investigation of the polycarbonate/crushed-rubber-particle interphase by nanoindentation. Journal of Applied Polymer Science, 2007. 103(4): p. 2687-2694.

[22] Lee, S.-H., et al., Evaluation of interphase properties in a cellulose fiber-reinforced polypropylene composite by nanoindentation and finite element analysis. Composites Part A: Applied Science and Manufacturing, 2007. 38(6): p. 1517-1524.

[23] Campo, M., A. Ureña, and J. Rams, Effect of silica coatings on interfacial mechanical properties in aluminium--SiC composites characterized by nanoindentation. Scripta Materialia, 2005. 52(10): p. 977-982.

[24] Ureña, A., et al., Characterization of interfacial mechanical properties in carbon fiber/alhuminium matrix composites by the nanoindentation technique. Composites Science and Technology, 2005. 65(13): p. 2025-2038.

[25] Kim, J.-K., M.-L. Sham, and J. Wu, Nanoscale characterisation of interphase in silane treated glass fibre composites. Composites Part A: Applied Science and Manufacturing, 2001. 32(5): p. $607-$ 618.

[26] Zheng S, Ashcroft IA, A depth sensing indentation study of the hardness and modulus of adhesives, Int J Adhesion \& Adhesives, 25, 2005, 67-76.

[27] L. Shen, T. Liu, P. Lv. Polishing effect on nanoindentation behavior of nylon 66 and its nanocomposites. Polymer Testing 2005;24(6):746.

[28] X. Li, B. Bhushan. A review of nanoindentation continuous stiffness measurement technique and its applications. Materials Characterization 2002;48(1):11.

[29] Oliver WC, Pharr GM, An improved technique for determining hardness and elastic-modulus using load and displacement sensing indentation experiments, J Mater Res, 1992, 7, 1564-1583.

[30] Koenig JL, Spectroscopy of polymers, $2^{\text {nd }}$ edition, Elsevier 1999. 
[31] Cognard JY, Davies P, Gineste B, Sohier L, Development of an improved adhesive test method for composite assembly design, Composites Science \& Technology - March 2005; 65 (3-4) 359-368.

[32] Créach'cadec R, Cognard J-Y, Heuzé T, On modelling the non-linear behaviour of thin adhesive films in bonded assemblies with interface elements, J. Adhesion Sci. \& Tech., 2008, available on-line.

[33] Lapique F, Radford K, Curing effects on viscosity and mechanical properties of a commercial epoxy resin adhesive, Int J Adhesion and Adhesives, Vol. 22, 4, 2002, 337-346

[34] Chaignaud S, Durability of elastomer/metal assemblies, PhD thesis Université de Toulon et du Var, October 2003 (in French).

[35] Socrates G, Infrared and Raman Characteristic Group Frequencies, Tables and Charts, Wiley, 3rd edition, 2001.

[36] Jeandrau JP, Analysis and design data for adhesively bonded joints, Int J Adhes \& Adhesives, 11, 2, April 1991, 71-79.

[37] Ducept F, Davies P, Gamby D, Mixed mode failure criteria for a glass/epoxy composite and an adhesively bonded composite/composite joint, Int J Adhesion \& Adhesives, 20, 2000, 233-244.

[38] J.Y. Cognard, F. Thomas, P. Verpeaux, An integrated approach to solving mechanical problems on parallel computers, Advances in Engineering Software, 31, 885-899, 2000.

[39] Cheikh M, Coorevits P, Loredo M., Modelling the stress vector continuity at the interface of bonded joints, Int. J. Adhesion \& Adhesives, 22, 249-257, 2001.

[40] Cognard J.Y., Créac'hcadec R., Davies P, Sohier L., Numerical modelling of the non-linear behavior of adhesively-bonded assemblies, in Innovation In Engineering Computational Structures Technology, Saxe-Coburg Publications, ISBN 1-874672-27-X, 225-247, 2006.

[41] Cognard J.Y., Numerical analysis of edge effects in adhesively-bonded assemblies. Application to the determination of the adhesive behaviour, Computers \& Structures, 2008 (accepted for publication). 


\section{List of Figure headings.}

Figure 1. a) Assembly fixture for 6 Arcan specimens in oven. b) Arcan samples with three thicknesses, sections after high pressure water-jet cutting.

Figure 2. Nano-indentation. a) Typical load-displacement plot, b) Schematic diagram showing indentation profile

Figure 3a. Two lines of indents from aluminium (lower) across interface into epoxy.

b. Calibration indent on aluminium substrate, c. Indent on epoxy.

Figure 4. a) Arcan fixture orientation, b) Adhesive specimen in Arcan test fixture, shear configuration $\left(90^{\circ}\right)$.(1) Loading fixture, (2) specimen, (3) clamping system, (4) support for clamp. c) Bonded specimen showing detail of beaks.

Figure 5: Zone studied and displacement field at $\mathrm{t}=60 \mathrm{~s}, 1.1 \mathrm{~mm}$ thick bondline

Figure 6: time evolution of the error indicator and relative displacement

Figure 7: Pure shear deformation of a thick adhesive joint

Figure 8. Results from preliminary Arcan series to examine reproducibility, pure shear, bond line thickness $1 \mathrm{~mm}$, four specimens.

Figure 9. SEM photos showing polished sections through joints

a) $0.61 \mathrm{~mm}$, b) $1.28 \mathrm{~mm}$. Points on photo a) indicate EDX analysis points.

Figure 10. a) Typical DSC recordings, b) Values of Tg versus joint thickness from DSC.

Figure 11. Nano-indentation across aluminium/adhesive interface.

Figure 12: a) Optical view of the cross section analysed by Raman scattering (x100 objective lens in white light). Substrates (white) at top and bottom of photo. Each black circle corresponds to a Raman spectrum recorded, in the adhesive, b): three Raman spectra along the cross section presented in figure $12 \mathrm{a}$, for $2.6,26.2$ and $49.8 \mu \mathrm{m}$ on the y axis.

Figure 13: Raman scattering spectra along cross section from $y=2.6$ (centre of adhesive) to $y=49.8 \mu \mathrm{m}$ (interface). Enlargement of two spectral regions: from 610 to $670 \mathrm{~cm}^{-1}$ and from 1580 to $1630 \mathrm{~cm}^{-1}$.

Figure 14: Evolution of the $\mathrm{nC}=\mathrm{C}$ Raman shift localized around $1600 \mathrm{~cm}^{-1}$ and evolution of the ratio of two bands at 630 and $639 \mathrm{~cm}^{-1}$ versus the analysed points along cross section, from centre (left of figure) to interface (right).

Figure 15. Typical tensile stress-strain plots parallel-sided film specimens, and mean modulus values with standard deviations (calculated over strain range 0.1-0.3\%) for thin and thick specimens. Six specimens were tested for each thickness range.

Figure 16. Strength results from tensile tests on films, dogbone specimens.

Figure 17. Influence of bond line thickness on stress-strain behaviour of joints.

a) Tension $\left(0^{\circ}\right)$, b) Tension/shear $\left(45^{\circ}\right)$, c) Shear $\left(90^{\circ}\right)$

Figure 18. Image of thick $(0.9 \mathrm{~mm})$ joint loaded in shear, just before failure

Figure 19. Beak (SEM photo), model and edge geometry.

Figure 20. Influence of the thickness of the joint on stress concentrations for different loading types. 
Figure 21. Calculated stress distributions in thin and thick bonded joints, a)Tension, b) Shear. 


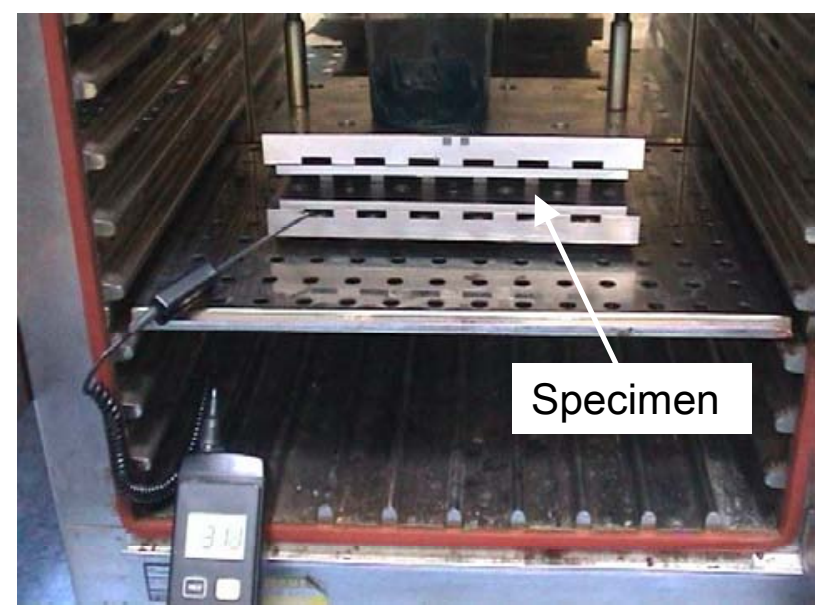

(a)

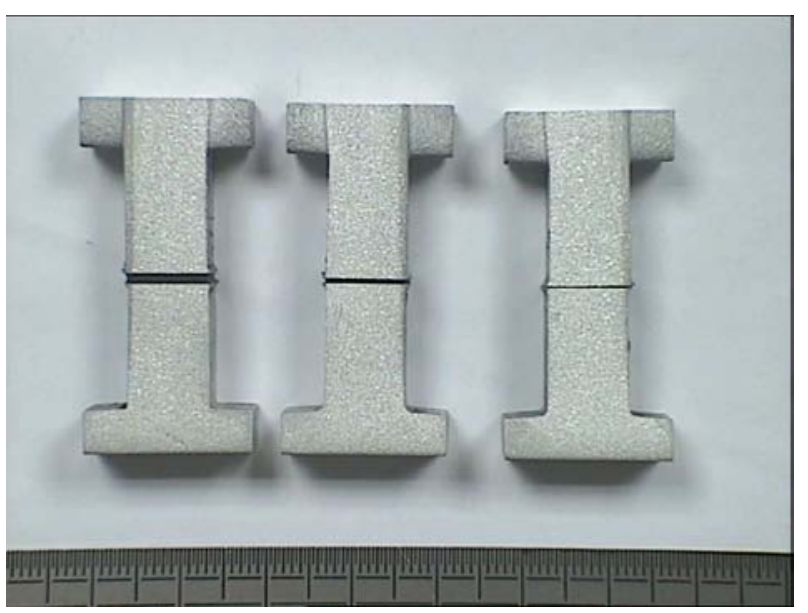

(b)

Figure 1. a) Assembly fixture for six Arcan specimens in oven.

b) sections through samples with three thicknesses 


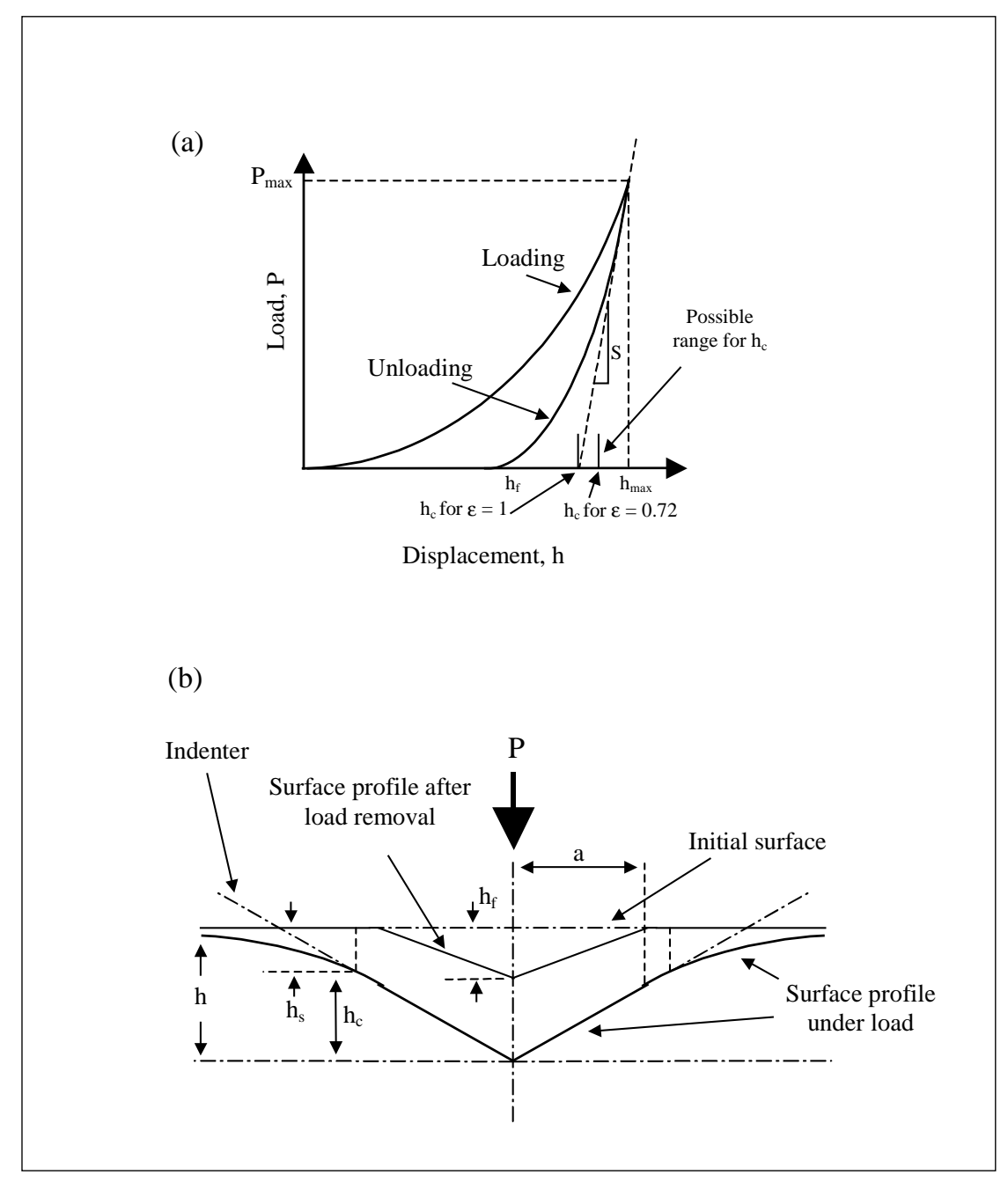

Figure 2. Nano-indentation. a) Typical load-displacement plot, b) Schematic diagram showing indentation profile 
(a)

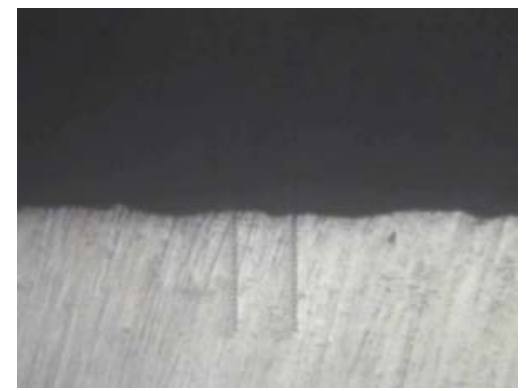

(b)

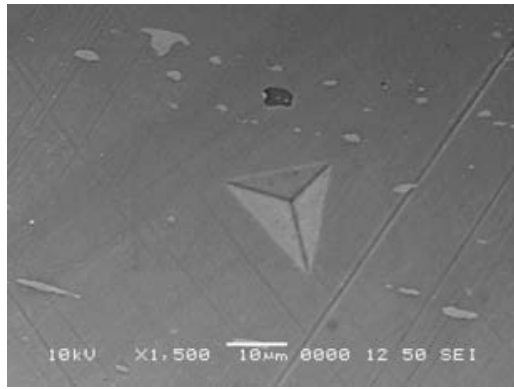

(c)

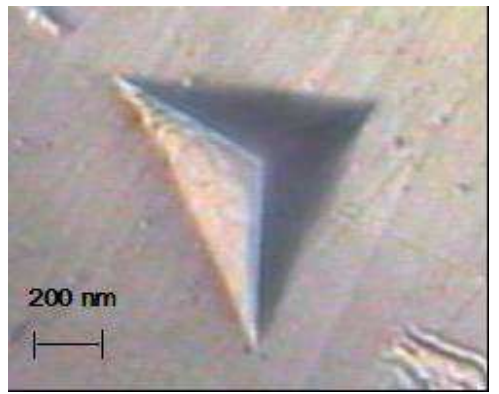

Figure 3

a. Two lines of indents from aluminium (lower) across interface into epoxy.

b. Calibration indent on aluminium substrate,

c. Indent in epoxy.

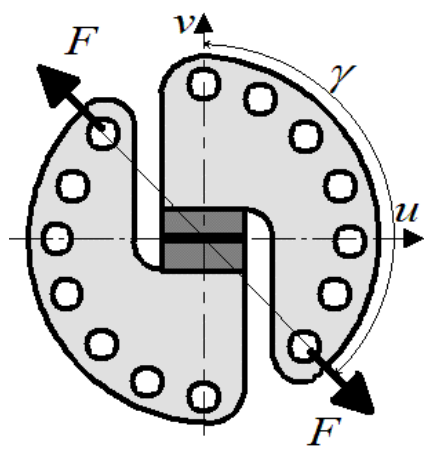

(a)

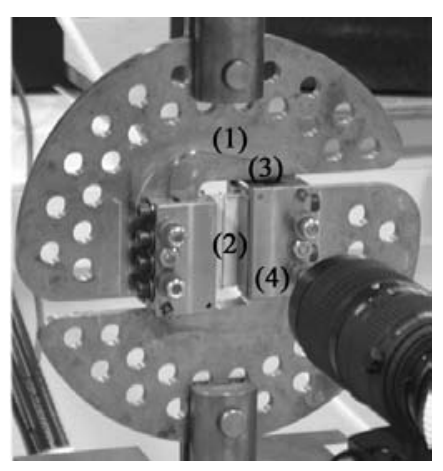

(b)

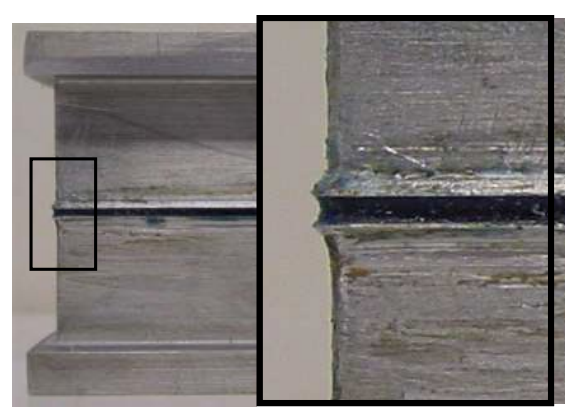

(C)

Figure 4. a) Arcan fixture orientation, b) Adhesive specimen in Arcan test fixture, shear configuration $\left(90^{\circ}\right)$.(1) Loading fixture, (2) specimen, (3) clamping system, (4) support for clamp. c) Bonded specimen showing detail of beaks. 


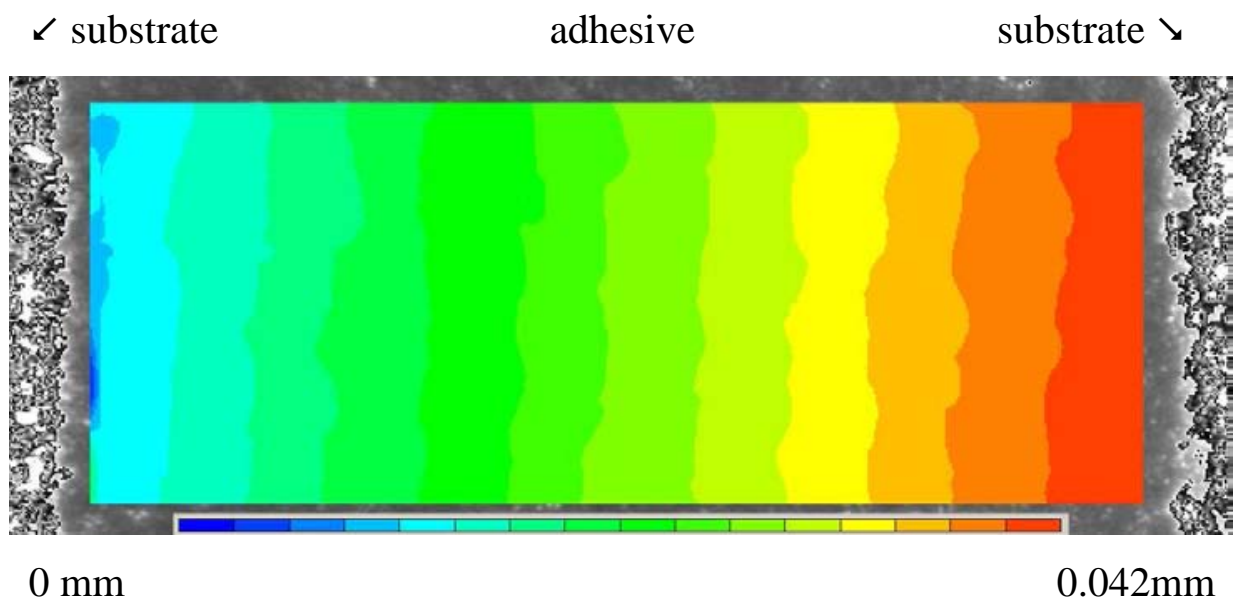

Figure 5: Zone studied and displacement field at $\mathrm{t}=60 \mathrm{~s}, 1.1 \mathrm{~mm}$ thick bondline

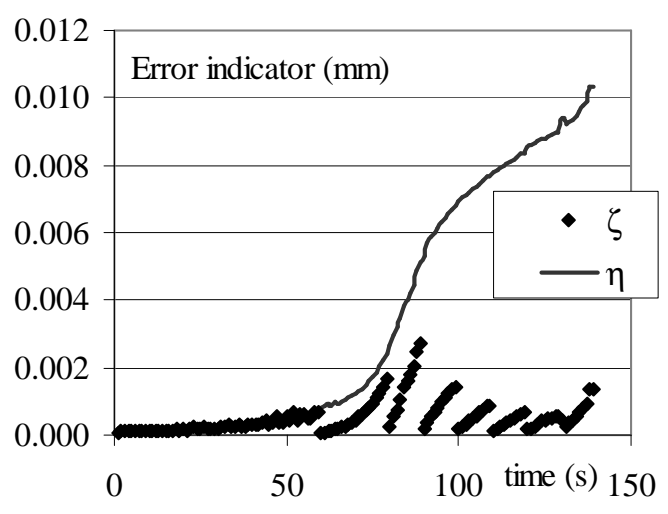

(a) error indicator

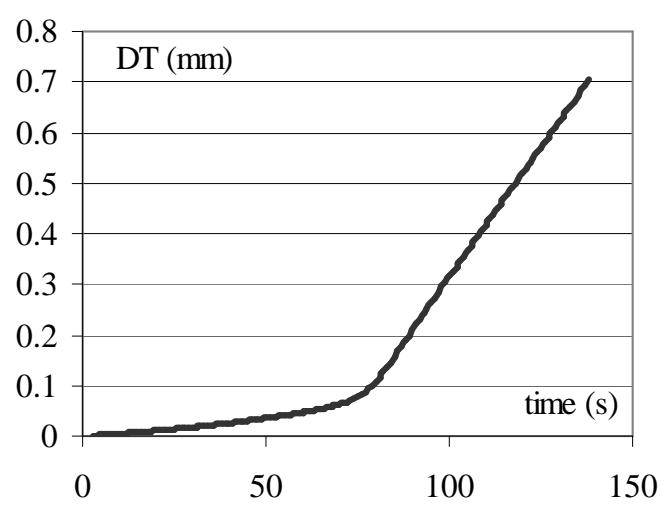

(b) relative displacement

Figure 6: time evolution of the error indicator and relative displacement 

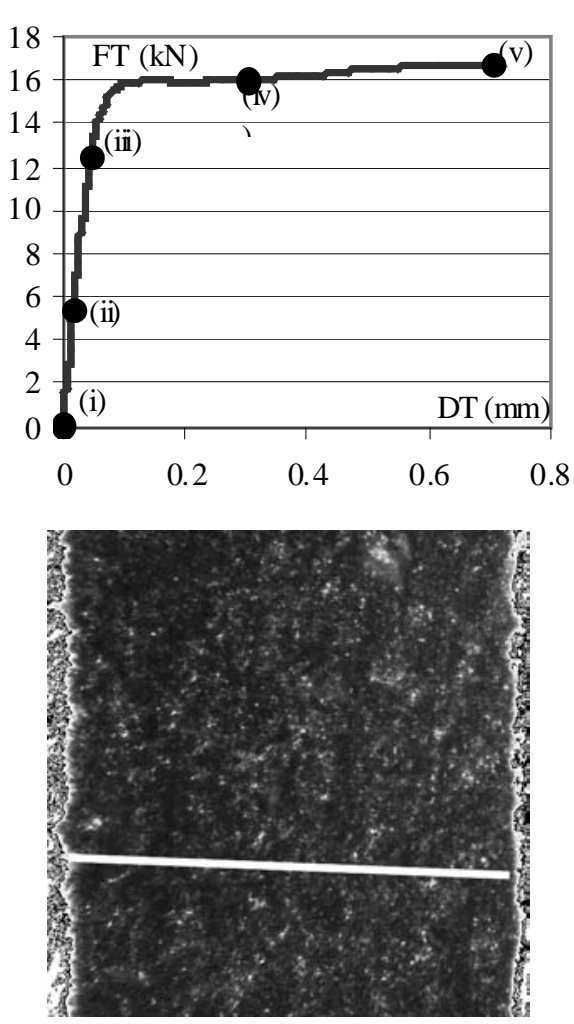

(iii)

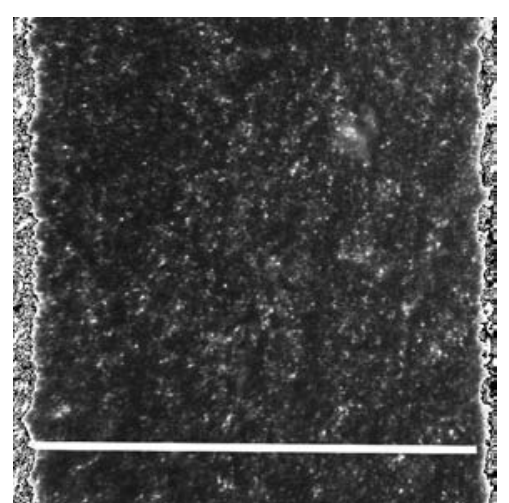

(i)

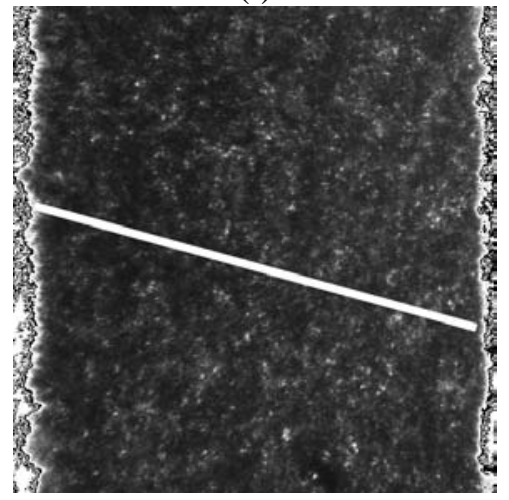

(iv)

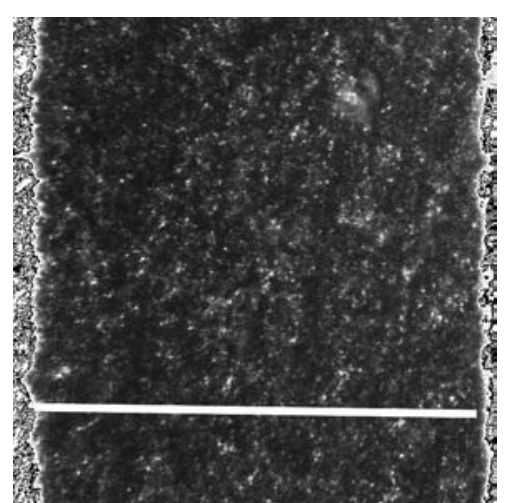

(ii)

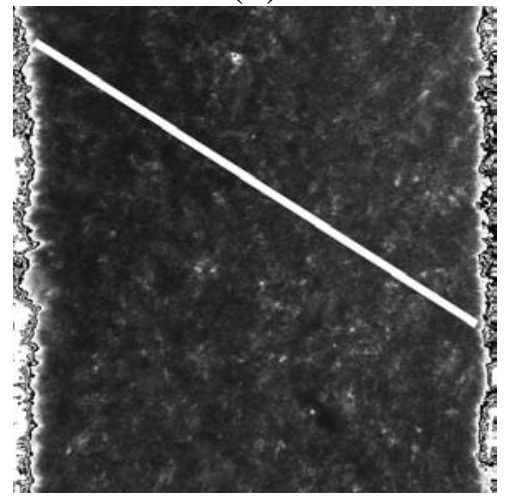

(v)

Figure 7: Pure shear deformation of a thick adhesive joint

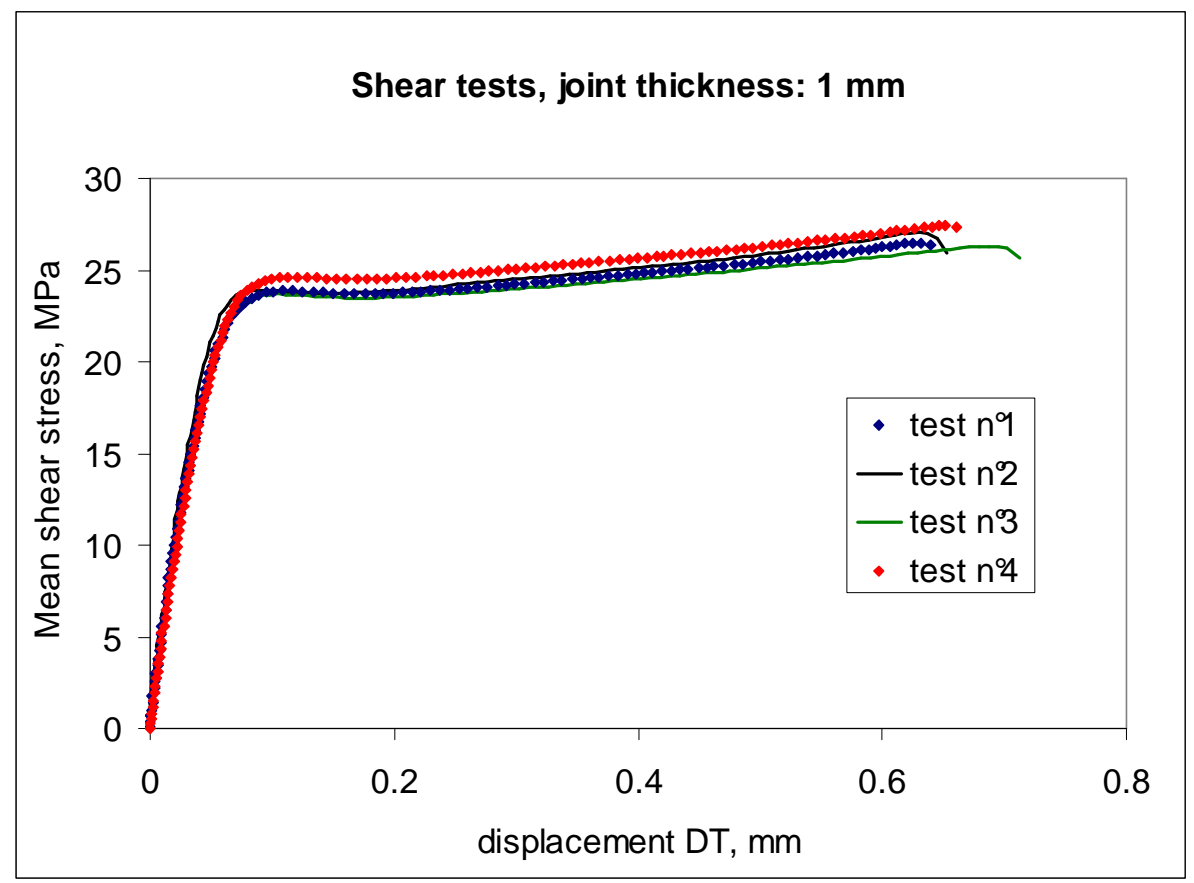

Figure 8. Results from preliminary Arcan series to examine reproducibility, shear, Bond-line thickness $1 \mathrm{~mm}$, four specimens. 


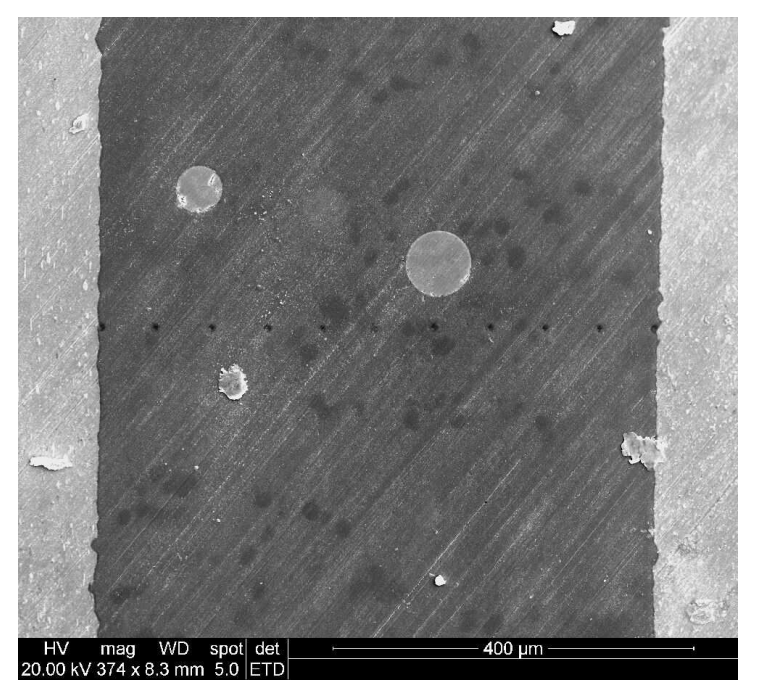

(a)

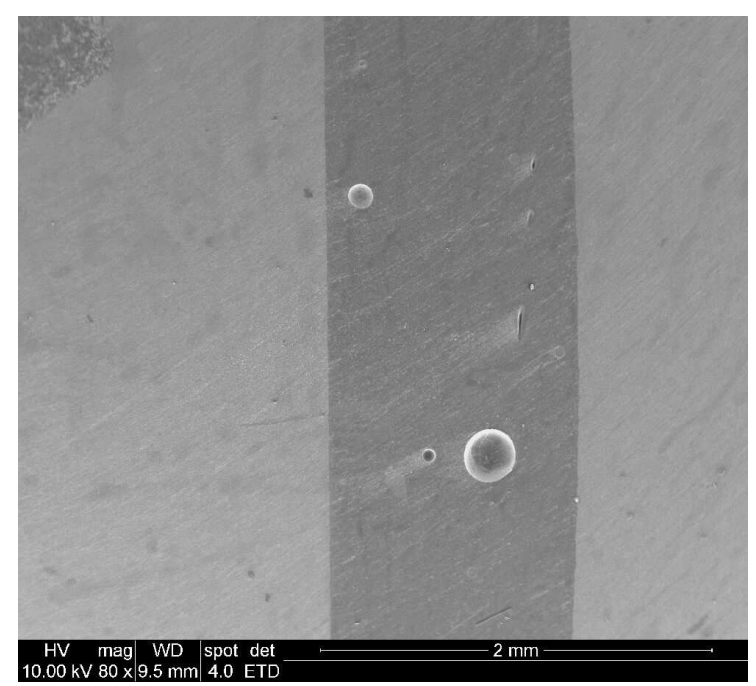

(b)

Figure 9. SEM photos showing polished sections through joints

$$
\text { a) } 0.61 \mathrm{~mm} \text {, b) } 1.28 \mathrm{~mm}
$$

Points on Figure 9a show EDX analysis points. 

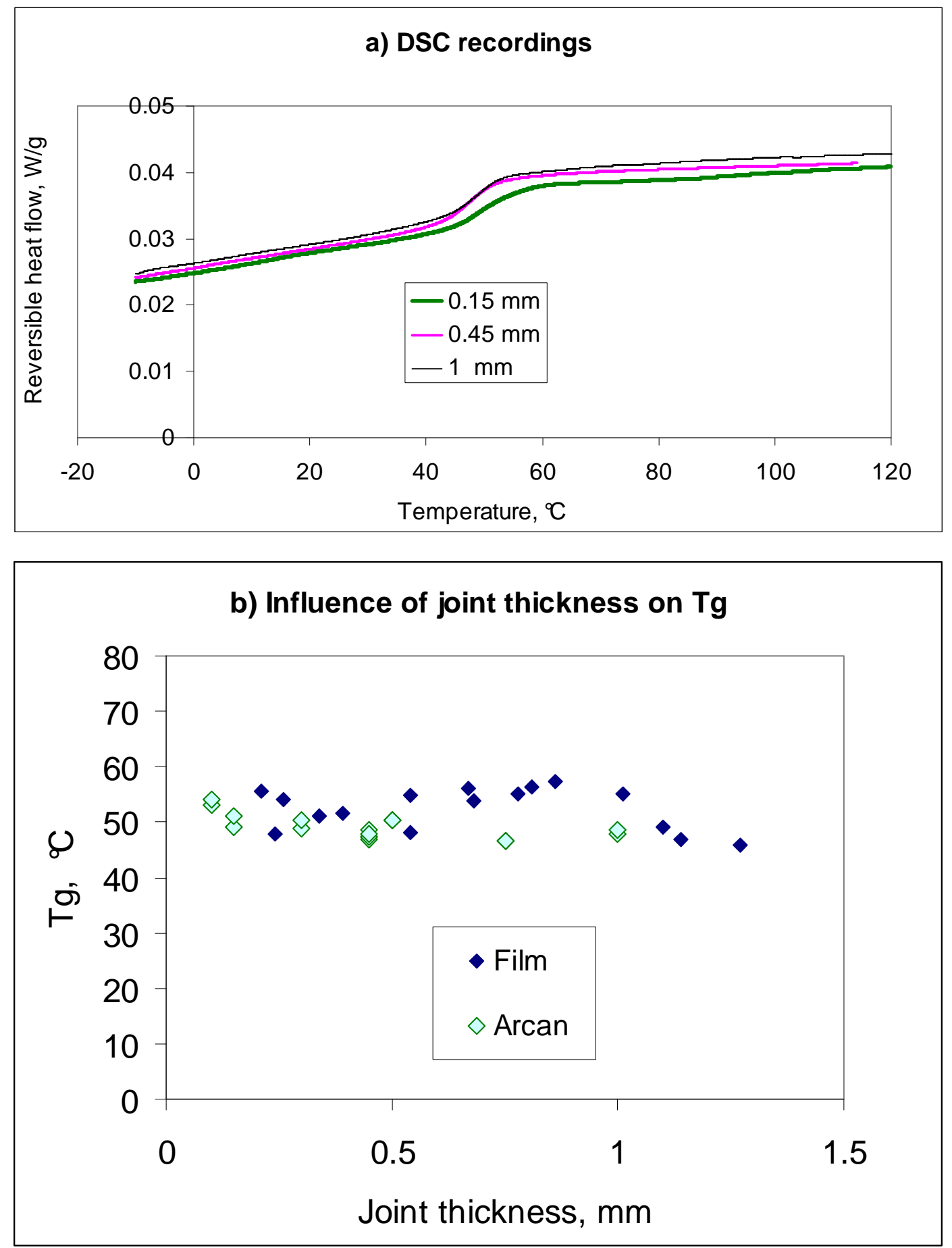

Figure 10. a) Typical DSC recordings, b) Values of Tg versus joint thickness from DSC. 


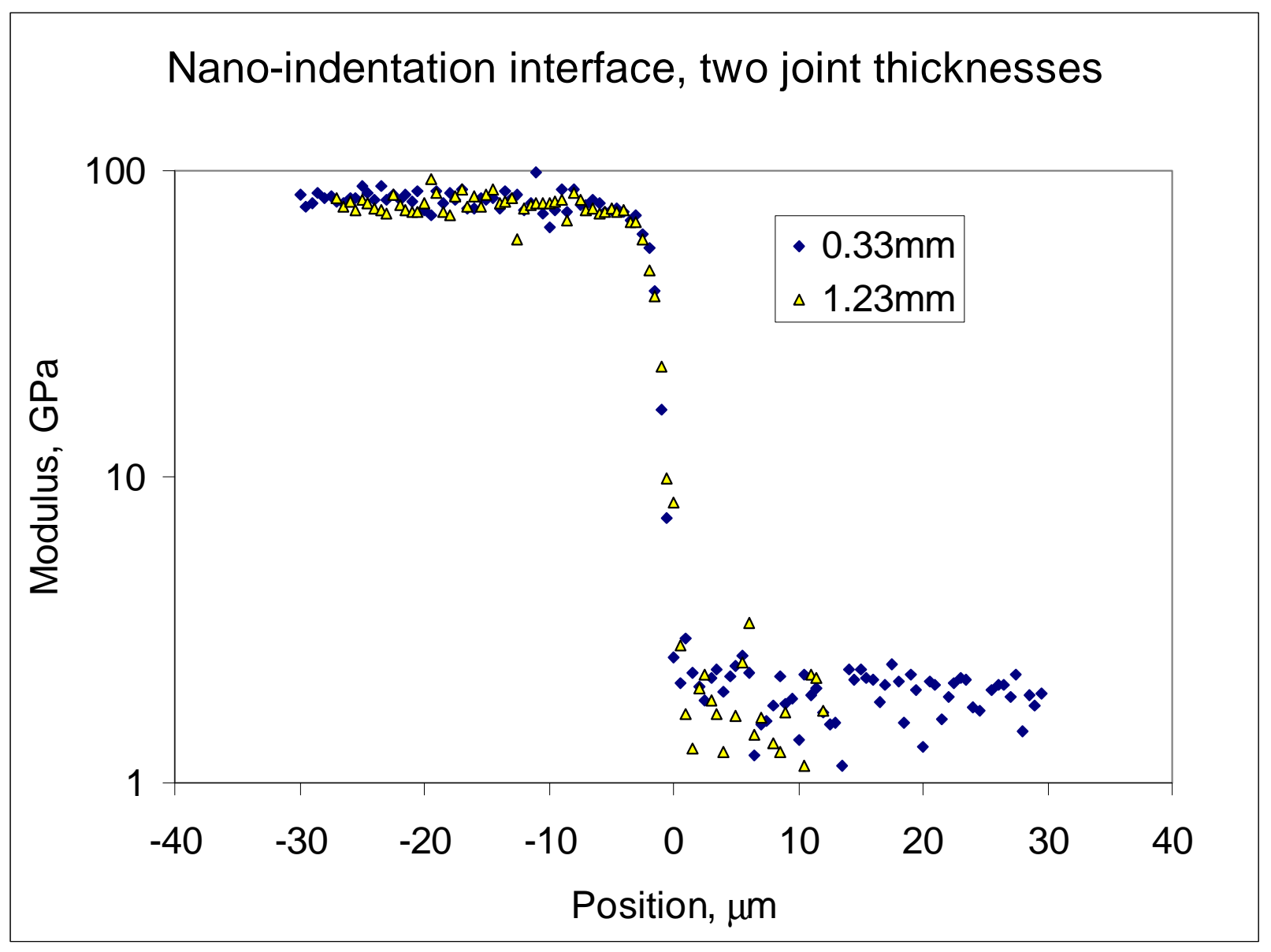

Figure 11. Nano-indentation across aluminium/adhesive interface.
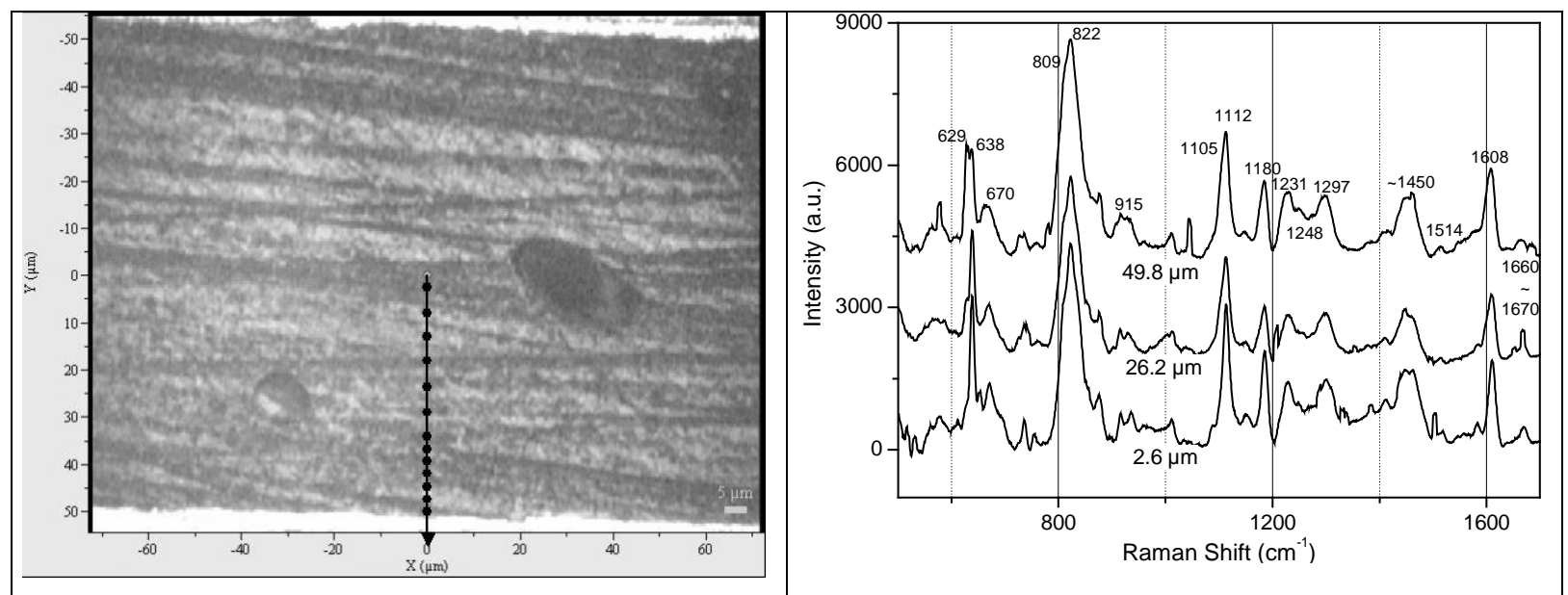

Figure 12: a) Optical view of the cross section analysed by Raman scattering (x100 objective lens in white light). Substrates (white) at top and bottom of photo. Each black circle 
corresponds to a Raman spectrum recorded in the adhesive. b) three Raman spectra along the cross section presented in figure $12 \mathrm{a}$, for $2.6,26.2$ and $49.8 \mu \mathrm{m}$ on the y axis.

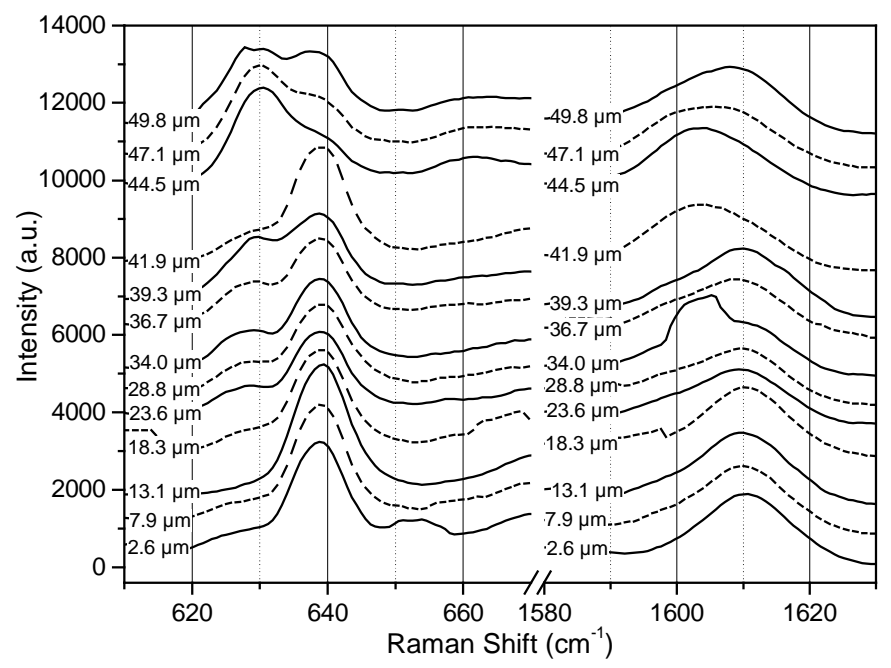

Figure 13: Raman scattering spectra along cross section from $y=2.6$ (centre of adhesive) to $\mathrm{y}=49.8 \mu \mathrm{m}$ (interface). Enlargement of two spectral regions: from 610 to $670 \mathrm{~cm}^{-1}$ and from 1580 to $1630 \mathrm{~cm}^{-1}$.

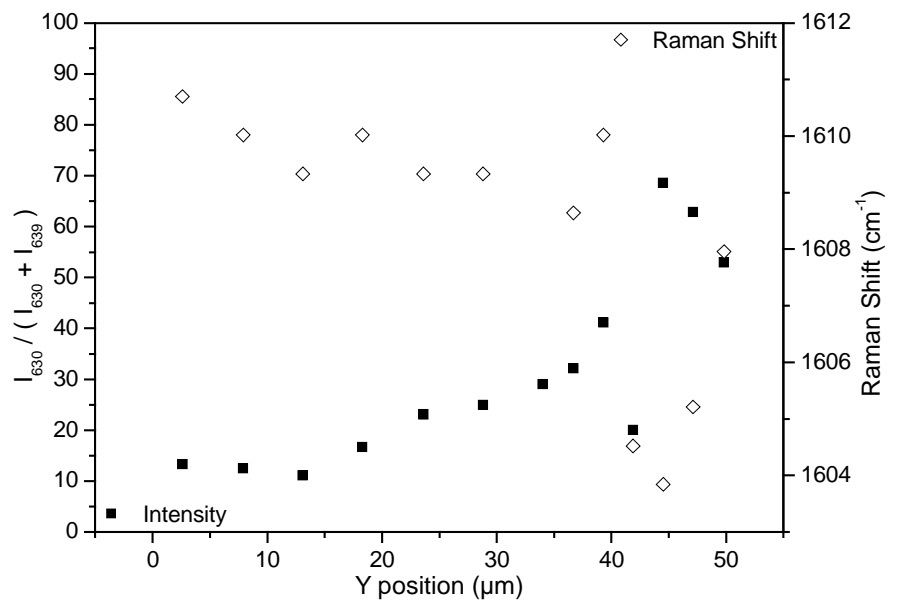

Figure 14: Evolution of the $v_{\mathrm{C}=\mathrm{C}}$ Raman shift localized around $1600 \mathrm{~cm}^{-1}$ and evolution of the ratio of two bands at 630 and $639 \mathrm{~cm}^{-1}$ versus the position on the cross section, from centre (left of figure) to interface (right). 


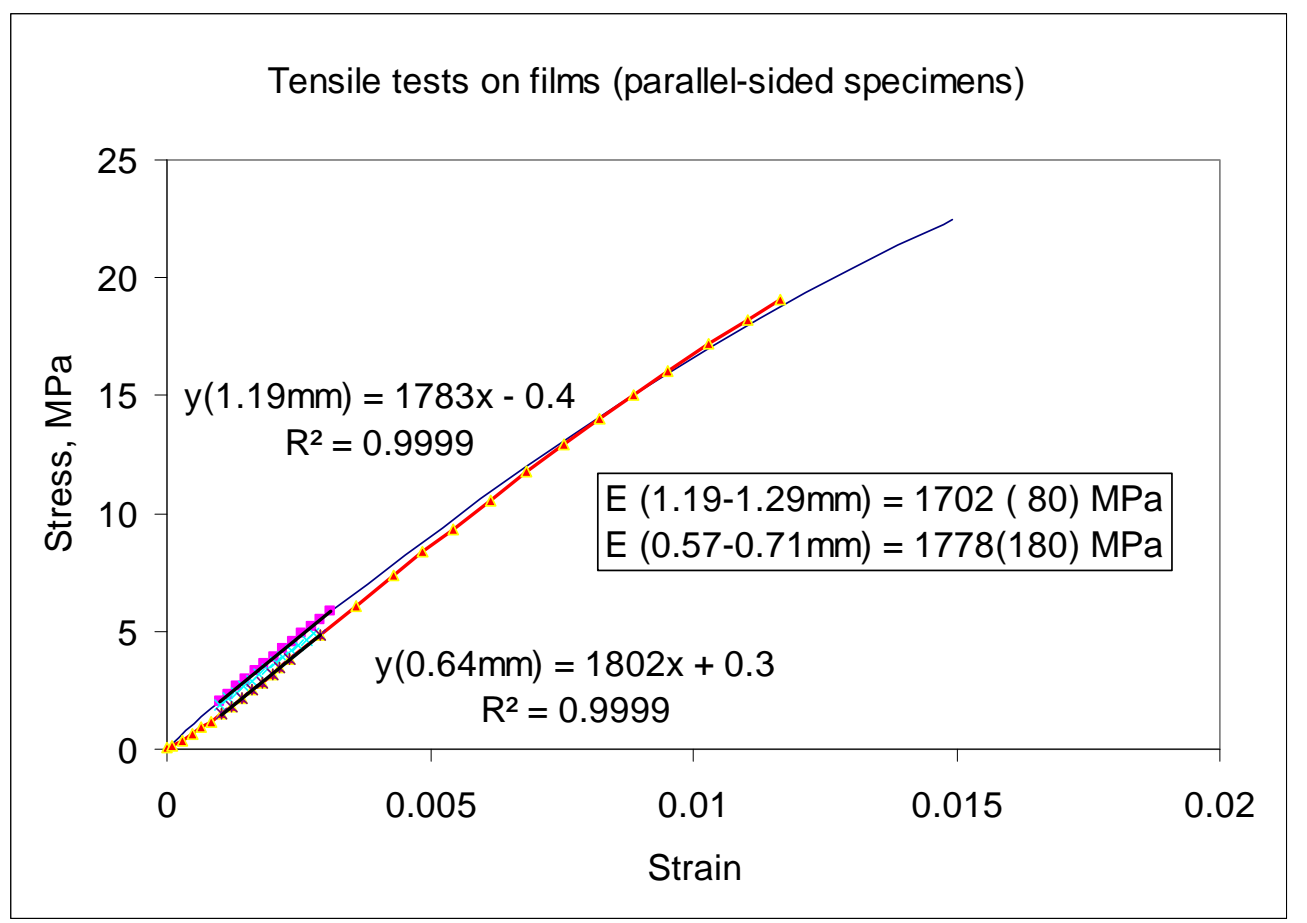

Figure 15. Typical tensile stress-strain plots parallel-sided film specimens, and mean modulus values with standard deviations (calculated over strain range $0.1-0.3 \%$ ) for thin and thick specimens. Six specimens were tested for each thickness range.

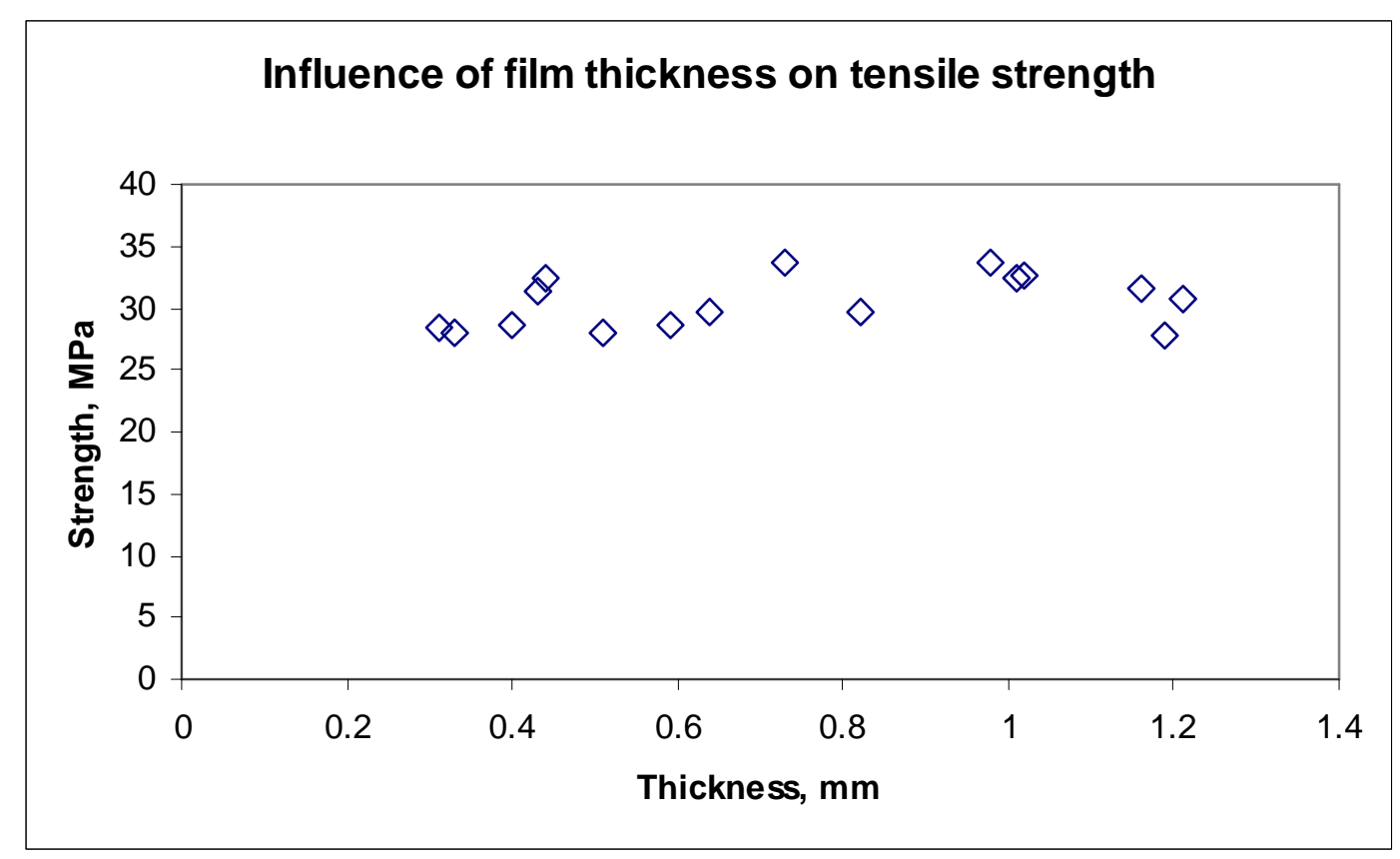

Figure 16. Strength results from tensile tests on films, dogbone specimens 

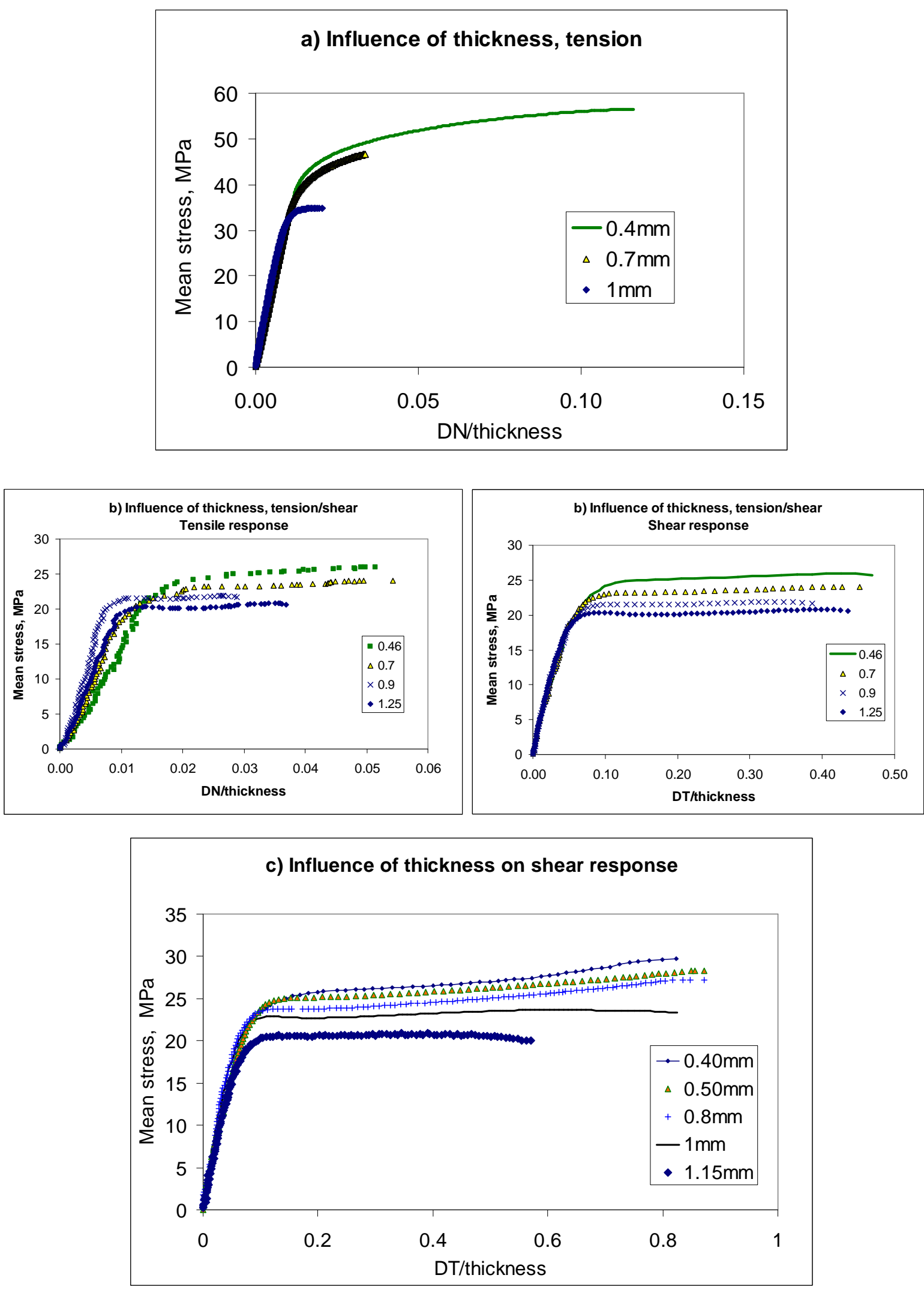

Figure 17. Influence of bond line thickness on stress-strain behaviour of joints.

a) Tension, b) tension/shear, c) shear 


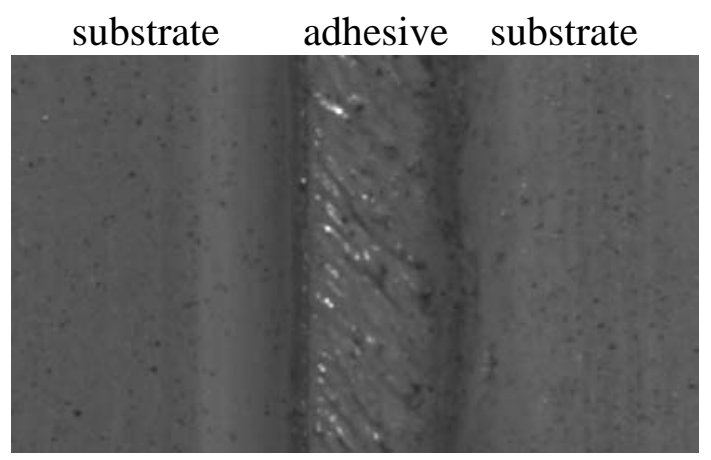

Figure 18. Image of thick $(0.9 \mathrm{~mm})$ joint loaded in shear, just before failure.

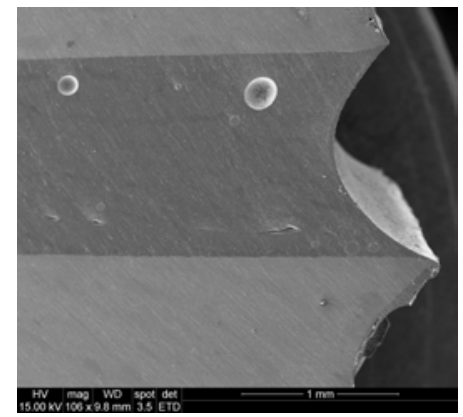

a) SEM photo of beak

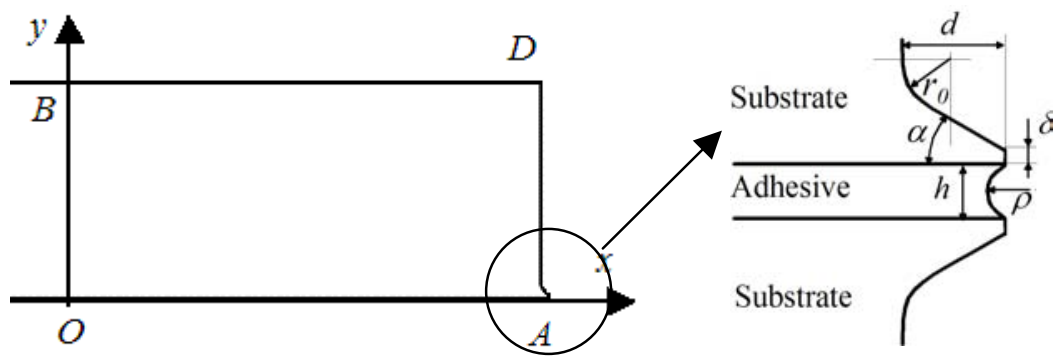

c) Edge geometry

Figure 19. Beak (SEM photo), model and edge geometry.

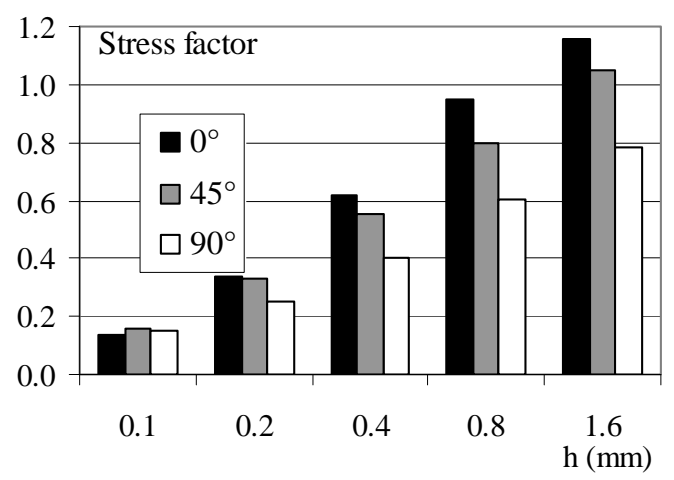

Figure 20. Influence of the joint thickness on stress concentrations for different loading types. 


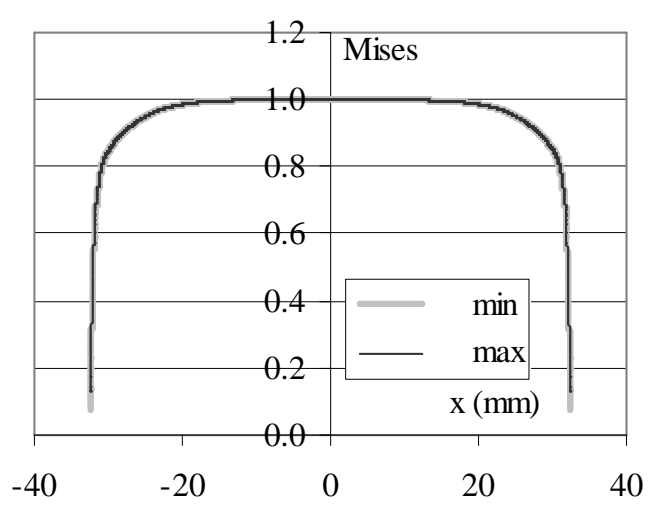

$\mathrm{h}=0.1 \mathrm{~mm}$

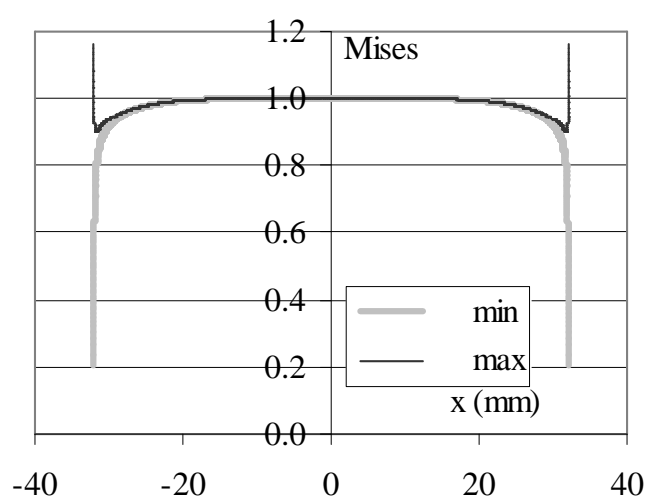

$\mathrm{h}=1.6 \mathrm{~mm}$

a) Tension
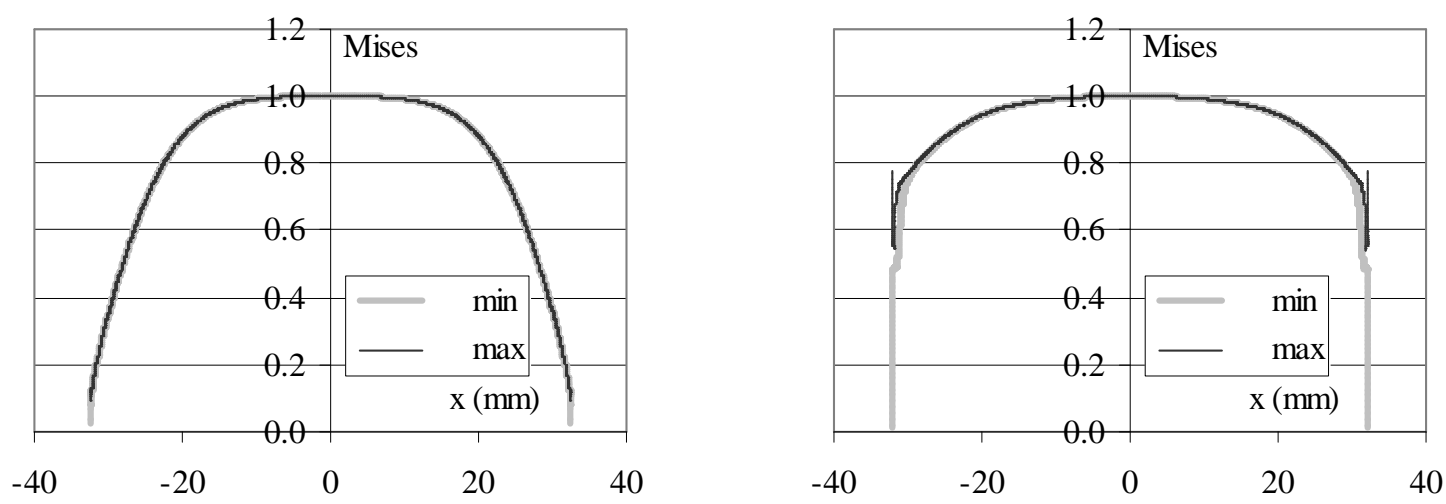

$\mathrm{h}=0.1 \mathrm{~mm}$

$\mathrm{h}=1.6 \mathrm{~mm}$

b) Shear

Figure 21. Calculated stress distributions in thin and thick bonded joints. 
